\title{
Article
}

\section{Preparation and Characterization of Transparent Polyimide Nanocomposite Films with Potential Applications as Spacecraft Antenna Substrates with Low Dielectric Features and Good Sustainability in Atomic-Oxygen Environments}

\author{
Yan Zhang ${ }^{1}$, Bo-han $\mathrm{Wu}^{2}{ }^{2}$, Han-li Wang ${ }^{3}$, Hao Wu ${ }^{1}$, Yuan-cheng An ${ }^{1}$, Xin-xin Zhi ${ }^{1}$ and Jin-gang Liu ${ }^{1, *(\mathbb{D})}$ \\ 1 Beijing Key Laboratory of Materials Utilization of Nonmetallic Minerals and Solid Wastes, \\ National Laboratory of Mineral Materials, School of Materials Science and Technology, \\ China University of Geosciences, Beijing 100083, China; 3003200016@cugb.edu.cn (Y.Z.); \\ 2003200021@cugb.edu.cn (H.W.); $2103190039 @$ cugb.edu.cn (Y.-c.A.); 3003200015@cugb.edu.cn (X.-x.Z.) \\ 2 Space Materials and Structure Protection Division, Beijing Institute of Spacecraft Environment Engineering, \\ Beijing 100094, China; wubohan@spacechina.com \\ 3 Shandong Huaxia Shenzhou New Material Co., Ltd., Zibo 256401, China; wh189333@huaxiashenzhou.com \\ * Correspondence: liujg@cugb.edu.cn; Tel.: +86-10-82322972
}

Citation: Zhang, Y.; Wu, B.-h.; Wang, H.-1.; Wu, H.; An, Y.-c.; Zhi, X.-x.; Liu, J.-g. Preparation and Characterization of Transparent Polyimide Nanocomposite Films with Potential Applications as Spacecraft Antenna Substrates with Low Dielectric Features and Good Sustainability in Atomic-Oxygen Environments. Nanomaterials 2021, 11, 1886. https://doi.org/10.3390/ nano11081886

Academic Editors: Mauro Zarrelli and Anna Borriello

Received: 2 July 2021

Accepted: 19 July 2021

Published: 23 July 2021

Publisher's Note: MDPI stays neutral with regard to jurisdictional claims in published maps and institutional affiliations.

Copyright: (C) 2021 by the authors Licensee MDPI, Basel, Switzerland. This article is an open access article distributed under the terms and conditions of the Creative Commons Attribution (CC BY) license (https:/ / creativecommons.org/licenses/by/ $4.0 /)$.

\begin{abstract}
Optically transparent polyimide (PI) films with good dielectric properties and longterm sustainability in atomic-oxygen $(\mathrm{AO})$ environments have been highly desired as antenna substrates in low earth orbit (LEO) aerospace applications. However, PI substrates with low dielectric constant (low- $\left.D_{\mathrm{k}}\right)$, low dielectric dissipation factor $\left(\right.$ low $\left.-D_{\mathrm{f}}\right)$ and high AO resistance have rarely been reported due to the difficulties in achieving both high AO survivability and good dielectric parameters simultaneously. In the present work, an intrinsically low- $D_{\mathrm{k}}$ and low- $D_{\mathrm{f}}$ optically transparent PI film matrix, poly[4, $4^{\prime}$-(hexafluoroisopropylidene)diphthalic anhydride-co-2,2-bis(4-(4aminophenoxy)phenyl)hexafluoropropane] (6FPI) was combined with a nanocage trisilanolphenyl polyhedral oligomeric silsesquioxane (TSP-POSS) additive in order to afford novel organic-inorganic nanocomposite films with enhanced AO-resistant properties and reduced dielectric parameters. The derived 6FPI/POSS films exhibited the $D_{\mathrm{k}}$ and $D_{\mathrm{f}}$ values as low as 2.52 and 0.006 at the frequency of $1 \mathrm{MHz}$, respectively. Meanwhile, the composite films showed good AO resistance with the erosion yield as low as $4.0 \times 10^{-25} \mathrm{~cm}^{3}$ /atom at the exposure flux of $4.02 \times 10^{20}$ atom $/ \mathrm{cm}^{2}$, which decreased by nearly one order of magnitude compared with the value of $3.0 \times 10^{-24} \mathrm{~cm}^{3} /$ atom of the standard PI-ref Kapton ${ }^{\circledR}$ film.
\end{abstract}

Keywords: polyimide substrate; atomic oxygen; dielectric constant; POSS; antenna

\section{Introduction}

Flexible antennas play important roles in low-earth orbit (LEO) spacecraft for spaceearth communications, data transmission, and navigation [1]. In most cases, the spaceborne antennas will contact the LEO environments in the whole life of the spacecraft. The severe space environments in LEO, including atomic oxygen (AO), thermal shock cycle in the range of $-120^{\circ} \mathrm{C} \sim 150{ }^{\circ} \mathrm{C}$, ionizing radiation, micrometeoroids, and so on will inevitably deteriorate the antenna materials, especially the common light-weighted polymeric or polymer composite antennas [2-5]. When the spacecraft cruised in LEO at the speed of $7.9 \mathrm{~km} / \mathrm{s}$, the impact energy between the collision of polymer antennas and the AO species might be as high as $5 \mathrm{eV}$. This usually causes severe corrosion of the polymer substrates in the antennas due to the dissociation of chemical bonds in the polymers by the highenergy impacts [6-10]. For example, for the common polyimide (PI) substrates derived from pyromellitic anhydride (PMDA) and 4,4'-oxydianline (ODA) (PIPMDA-ODA), which are most widely used at present in spacecraft antennas, as shown in Figure 1, the molecular structure 
is mainly composed of $\mathrm{C}-\mathrm{N}$ bond (dissociation energy: $3.2 \mathrm{eV}$ ), $\mathrm{C}_{6} \mathrm{H}_{5}-\mathrm{H}$ bond (dissociation energy: $4.8 \mathrm{eV}$ ), and $-\mathrm{C}_{6} \mathrm{H}_{5}-\mathrm{C}(=\mathrm{O})$ - bond (dissociation energy: $\left.3.9 \mathrm{eV}\right)$ [11]. Thus, serious corrosion might occur when the PIPMDA-ODA substrates were impacted by AO, which might greatly decrease the servicing life of the antenna [12]. The poor AO resistance of standard PI PMDA-ODA substrates undoubtedly prohibited the applications in LEO spacecraft antennas. On the other hand, for the antenna applications, low dielectric constant (low- $D_{\mathrm{k}}$ ) and low dielectric dissipation factor $\left(\right.$ low $\left.-D_{\mathrm{f}}\right)$ features are often required for the polymeric substrates in order to achieve a high signal transmission speed (low signal delay) and low crosstalk $[13,14]$. In addition, the low dielectric properties could also provide the antenna with better impedance matching and higher gain compared to conventional high-dielectric-

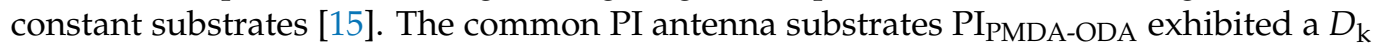
and $D_{\mathrm{f}}$ value of 3.2 and 0.02 at $1 \mathrm{MHz}$ frequency, respectively [16-18]. Thus, either the poor AO resistance or the high dielectric properties of the current PI PMDA-ODA substrates could not meet the property requirements of advanced antennas for LEO spacecraft.

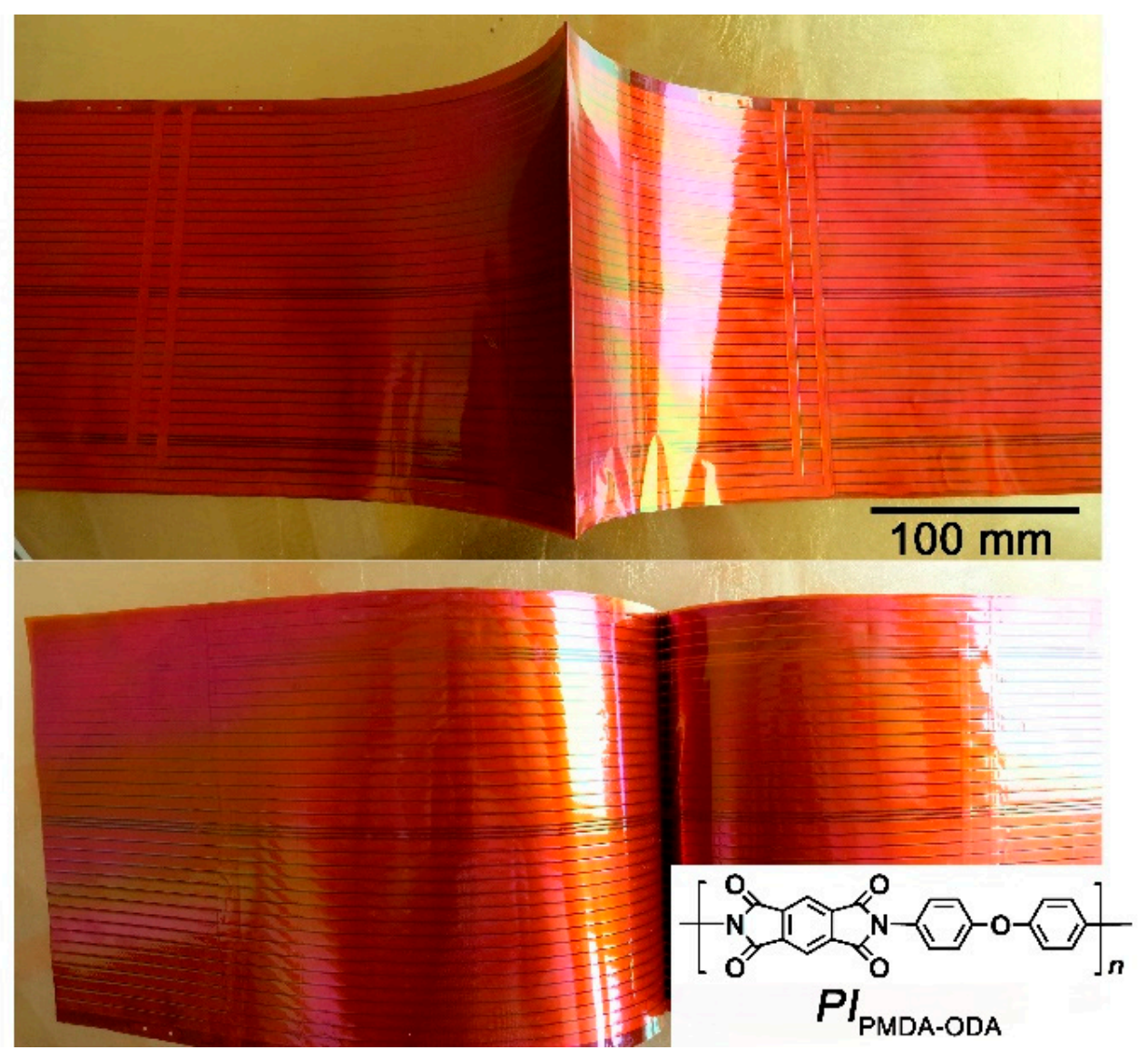

Figure 1. LEO spacecraft antennas based on PIPMDA-ODA substrates.

Recently, Meador and coworkers reported the pioneering work on the development of ultra-low- $D_{\mathrm{k}}$ PI aerogels as substrates for lightweight patch antennas for potential aerospace applications $[19,20]$. Relatively low $D_{\mathrm{k}}$ values as low as 1.16 were obtained from PI aerogels prepared by cross-linking $3,3^{\prime}, 4,4^{\prime}$-biphenylenetetracarboxylic dianhydride (BPDA) and 2,2'-dimethylbenzidine (DMBZ) with 1,3,5-triaminophenoxybenzene (TAB). It could be deduced from the molecular structures of the derived PI aerogels that the antennas made from the BPDA-DMBZ-TAB system might be sensitive to AO exposure and the applications of such antennas in LEO spacecraft might be of great challenge. In our previous work, we developed a series of AO-resistant PI aerogels for the potential antenna applications from BPDA, DMBZ, an aromatic diamine containing pendant polyhedral oligomeric silsesquioxane (POSS) units, and a POSS-containing crosslinker, 
octa(aminophenyl)silsesquioxane (OAPS) [21]. The inorganic-organic hybrid POSS components endowed the PI aerogels with excellent $\mathrm{AO}$ resistance. However, the dielectric properties of the POSS-PI aerogels were not mentioned.

In the current work, in order to remedy the poor AO resistance and relatively high $D_{\mathrm{k}}$ values of the common PI antenna substrates, a series of PI composite substrates were developed with fluoro-containing PI as matrix and trisilanolphenyl-POSS (TSP-POSS) as additive. First, the incorporation of fluorinated blocks has been well established to be able to decrease the $D_{\mathrm{k}}$ values of the PIs due to the low molar polarizability or high electronegativity of fluoro-containing substituents [22]. Secondly, the incorporation of POSS, especially the highly polar TSP-POSS additives could efficiently increase the AOresistant properties of the PI composites [23]. Thirdly, the nano-caged nature of POSS could decrease the density of the PI composite films via the confined air, thus could further decrease the $D_{\mathrm{k}}$ values of the PI composites [24]. The effect of the TSP-POSS additive on the comprehensive of PI composite substrates, especially on the dielectric properties and $\mathrm{AO}$ erosion properties were investigated in detail.

\section{Materials and Methods}

\subsection{Materials}

Fluoro-containing monomers, including 4, $4^{\prime}$-(hexafluoroisopropylidene)diphthalic anhydride (6FDA) and 2,2-bis[4-(4-aminophenoxy)phenyl]hexafluoropropane (BDAF) were all purchased from Daikin Chemicals (Tokyo, Japan). The dianhydride 6FDA was pretreated in a vacuum at $180^{\circ} \mathrm{C}$ for $10 \mathrm{~h}$, while the diamine BDAF was used without further treatment. Trisilanolphenyl-POSS (TSP-POSS) was purchased from Hybrid Plastics, Co., Ltd. (Hattiesburg, MS, USA). The ultra-dry $N, N$-dimethylacetamide (DMAc) was purchased from Beijing Innochem Science \& Technology Co., Ltd. (Beijing, China). The other reagent-grade chemicals were all purchased from Phentex (Tianjin) Fine Chemicals Co., Ltd. (Tianjin, China).

\subsection{Measurements}

A Brookfield DV-II+ Pro viscometer (Ametek, Middleboro, MA, USA) was used to measure the absolute viscosities of the poly(amic acid) (PAA) solutions, and the temperature was controlled at $25^{\circ} \mathrm{C}$. Attenuated total reflectance Fourier transform infrared (ATR-FTIR) spectra were recorded on a Bruker Tensor-27 FT-IR spectrometer (Ettlingen, Germany) at a resolution of $2 \mathrm{~cm}^{-1}$. Wide-angle X-ray diffraction (XRD) was obtained on a Bruker D8 advanceX diffractometer (Ettlingen, Germany) using $\mathrm{Cu}-\mathrm{K} \alpha 1$ radiation. An SCALab220iXL electron spectrometer (Thermo Fisher Scientific, Waltham, MA, USA) was used to obtain the X-ray photoelectron spectroscopy (XPS), under the monochromatic $\mathrm{MgK} \alpha$ radiation. The surface morphology was obtained on a Technex Lab Tiny-SEM 1540 field-emission scanning electron microscope (FE-SEM) (Tokyo, Japan) and a Bruker Multimode 8 atomic force microscopy (AFM) microscope (Santa Babara, CA, USA).

The optical transmittance of the films was measured on a Hitachi U-3210 Ultravioletvisible (UV-Vis) spectrophotometer (Hitachi, Ltd., Tokyo, Japan). The color parameters including yellow index (YI) and haze of the PI films at a thickness of $25 \mu \mathrm{m}$ were measured by an X-rite color i7 spectrophotometer (Grand Rapids, MI, USA). Among the obtained color parameters, the meaning of each parameter is as follows: $L^{*}$ is the lightness, where 100 implies white and 0 indicates black; $a^{*}$ : positive value means red, negative means green; $b^{*}$ : positive value was yellow, negative was blue. A Metricon MODEL 2010/M prism coupler (Pennington, NJ, USA) was used to measure the refractive index of the PI film at the wavelength of $1310 \mathrm{~nm}$. The average refractive index $\left(n_{\mathrm{AV}}\right)$ was calculated according to Equation (1):

$$
n_{\mathrm{AV}}=\left(2 n_{\mathrm{TE}}+n_{\mathrm{TM}}\right) / 3
$$


where, $n_{\mathrm{TE}}$ was the in-plane refractive index that was determined by linearly polarized laser light parallel to the film plane; $n_{\mathrm{TM}}$ was the out-of-plane refractive index, which was determined by linearly polarized laser light perpendicular to the film plane.

The thermal stability of the PI films was measured by thermogravimetric analysis (TGA) on a TA-Q50 thermal analysis system (TA Instruments, New Castle, DE, USA) at a heating rate of $20^{\circ} \mathrm{C} / \mathrm{min}$ under nitrogen ranged from $40{ }^{\circ} \mathrm{C}$ to $760{ }^{\circ} \mathrm{C}$. Differential scanning calorimetry (DSC) was conducted on the PI films using a TA-Q100 thermal analysis system in a standard aluminum crucible at a heating rate of $10^{\circ} \mathrm{C} / \mathrm{min}$ in nitrogen. The dimensional thermal stability of the PI films was tested with a thermomechanical analyzer (TMA) using a TA-Q400 thermal analysis system (TA Instruments, New Castle, DE, USA) in nitrogen at a heating rate of $10{ }^{\circ} \mathrm{C} / \mathrm{min}$. The coefficients of linear thermal expansion (CTE) of the PI films in the range of $50-200{ }^{\circ} \mathrm{C}$ were recorded.

The dielectric properties of the PI composite films were measured using an Agilent 4294A precise impedance analyzer (Palo Alto, CA, USA) at room temperature. The test frequency range is $10^{3}-10^{6} \mathrm{~Hz}$. The dielectric constant of PI films was calculated by the following Equation (2) [25]:

$$
D_{\mathrm{k}}=\frac{C d}{D_{0} A}
$$

where, $D_{\mathrm{k}}$ is the dielectric constant; $C$ is the capacitance $(\mathrm{F}) ; d$ is the thickness of the sample (m); $D_{0}$ is the dielectric constant of vacuum, $8.854 \times 10^{-12} \mathrm{~F} / \mathrm{m} ; A$ is the area of the sample $\left(\mathrm{m}^{2}\right)$.

The atomic oxygen (AO) erosion performance of PI films was obtained in a groundbased $\mathrm{AO}$ effects simulation facility in the Beijing Institute of Spacecraft Environment Engineering [12]. The size of the PI film sample was $20 \times 20 \times 0.05 \mathrm{~mm}^{3}$. The total AO fluence for this test was $4.02 \times 10^{20}$ atoms $/ \mathrm{cm}^{2}$, and the mass loss of PI films after AO erosion was recorded. The erosion yield $\left(E_{\mathrm{s}}\right)$ of the PI sample is calculated by the following Equation (3) [26]:

$$
E_{\mathrm{s}}=\frac{\Delta M_{\mathrm{s}}}{A_{\mathrm{s}} \rho_{\mathrm{s}} F}
$$

where, $E_{\mathrm{s}}=$ erosion yield of PI sample $\left(\mathrm{cm}^{3} /\right.$ atom $) ; \Delta M_{\mathrm{s}}=$ mass loss of PI sample $(\mathrm{g})$; $A_{\mathrm{S}}=$ surface area of the PI sample exposed to AO $\left(\mathrm{cm}^{2}\right) ; \rho_{\mathrm{s}}=$ density of the sample $\left(\mathrm{g} / \mathrm{cm}^{3}\right) ; F=$ AO fluence (atoms $\left./ \mathrm{cm}^{2}\right)$. As Kapton ${ }^{\circledR}$ film has a specific erosion yield of $3.0 \times 10^{-24} \mathrm{~cm}^{3} /$ atom [27], and all the present PI samples in this test are supposed to possess similar density and exposure area with Kapton ${ }^{\circledR}$ film, therefore, the simplified Equation (4) could be used to calculate the $E_{\mathrm{S}}$ of the PIs:

$$
E_{\mathrm{s}}=\frac{\Delta M_{\mathrm{s}}}{\Delta M_{\text {Kapton }}} E_{\text {Kapton }}
$$

where, $E_{\text {Kapton }}$ was the erosion yield of Kapton ${ }^{\circledR}, 3.0 \times 10^{-24} \mathrm{~cm}^{3} /$ atom; $\Delta M_{\text {Kapton }}$ was the mass loss of Kapton ${ }^{\circledR}$.

\subsection{Synthesis of Poly(amic acid)s and Preparation of PI Composite Films}

A series of fluoro-containing PI films combined with different loading content of TSPPOSS additives $(0,5 \mathrm{wt} \%, 10 \mathrm{wt} \%, 15 \mathrm{wt} \%, 20 \mathrm{wt} \%$, and $25 \mathrm{wt} \%$ based on the total solid films) were designed and prepared. For this target, the poly(amic acid) (PAA) precursors with the TSP-POSS fillers were prepared first. Then, the PAA/TSP-POSS precursors were thermally dehydrated to finish the imidization reaction to afford the final PI/TSP-POSS composite films. The derived PAA solutions were named as "6FPAA- $X$ ", where "6FPAA" stands for the fluoro-containing PAA and " $X$ " represents the weight percent content of the TSP-POSS additives. The afforded PI composites films were named as "6FPI-X", where "6FPI" stands for the fluoro-containing PI matrix and " $\mathrm{X}$ " stands for the weight percent content of the TSP-POSS additives in the composite films. The detailed synthesis procedure could be explained by the preparation procedure of 6 FPI- 5 . First, BDAF ( $51.8450 \mathrm{~g}$, 
$100 \mathrm{mmol})$ and TSP-POSS $(5.0668 \mathrm{~g}, 5.44 \mathrm{mmol})$ were added into a $1000-\mathrm{mL}$ four-necked flask equipped with a cold-water bath, an anchor-type mechanical stirrer (Shanghai Shupei Laboratory Equipment Co., Ltd, Shanghai, China), and a nitrogen inlet and outlet. Then, the ultra-dry DMAc solvent (400.0 g) was added to the flask. The mixture was stirred at $10^{\circ} \mathrm{C}$ for $15 \mathrm{~min}$ under a nitrogen flow $(20 \mathrm{~mL} / \mathrm{min})$ to afford a clear solution. Subsequently, 6FDA (44.4240 g, $100 \mathrm{mmol})$ was added together with an additional DMAc (60.0 g). The solid content of the polymerization system was $18 \mathrm{wt} \%$. After $3 \mathrm{~h}$, the cold-water bath was removed. The reaction mixture was stirred at room temperature for another $20 \mathrm{~h}$. Then, the afforded viscous and clear 6FPAA- 5 solution was diluted to be $15 \mathrm{wt} \%$. The obtained solution was filtered through a $0.50-\mu \mathrm{m}$ polytetrafluoroethylene (PTFE) filter to remove any undissolved impurities.

The other 6FPAA-X solutions were synthesized on the basis of the procedures mentioned above. The detailed formulas for the preparation of the polymers were listed in Table 1.

Table 1. Formulas for the synthesis of 6FPAA-X solutions.

\begin{tabular}{|c|c|c|c|c|}
\hline PAA & $\begin{array}{c}\text { 6FDA } \\
(M=444.24 \mathrm{~g} / \mathrm{mol})\end{array}$ & $\begin{array}{c}\text { BDAF } \\
(M=518.45 \mathrm{~g} / \mathrm{mol})\end{array}$ & $\begin{array}{c}\text { TSP-POSS } \\
(M=931.34 \mathrm{~g} / \mathrm{mol})\end{array}$ & $\begin{array}{l}\text { DMAc } \\
\text { (g) }\end{array}$ \\
\hline 6FPAA-0 & $44.4240 \mathrm{~g}(100 \mathrm{mmol})$ & $51.8450 \mathrm{~g}(100 \mathrm{mmol})$ & 0 & 439.0 \\
\hline 6FPAA-10 & $44.4240 \mathrm{~g}(100 \mathrm{mmol})$ & $51.8450 \mathrm{~g}(100 \mathrm{mmol})$ & $10.6966 \mathrm{~g}(11.48 \mathrm{mmol})$ & 487.0 \\
\hline 6FPAA-15 & $44.4240 \mathrm{~g}(100 \mathrm{mmol})$ & $51.8450 \mathrm{~g}(100 \mathrm{mmol})$ & $16.9886 \mathrm{~g}(18.24 \mathrm{mmol})$ & 516.0 \\
\hline 6FPAA-20 & $44.4240 \mathrm{~g}(100 \mathrm{mmol})$ & $51.8450 \mathrm{~g}(100 \mathrm{mmol})$ & $24.0673 \mathrm{~g}(25.84 \mathrm{mmol})$ & 548.0 \\
\hline 6FPAA-25 & $44.4240 \mathrm{~g}(100 \mathrm{mmol})$ & $51.8450 \mathrm{~g}(100 \mathrm{mmol})$ & $32.0897 \mathrm{~g}(34.46 \mathrm{mmol})$ & 585.0 \\
\hline
\end{tabular}

Secondly, the 6FPI-5 film was prepared by using the 6FPAA-5 as the starting materials. The purified and de-foamed 6FPAA-5 solution was spin-coated on a quartz wafer with a diameter of $10.16 \mathrm{~cm}$ (4 inches). The thicknesses of the PI films from $10 \mu \mathrm{m}$ to $100 \mu \mathrm{m}$ were adjusted by the spin-coating parameters. The quartz wafer with the coated 6FPAA-5 solution were placed in a clean oven circulated with dry nitrogen and then thermally baked with the conditions of $80^{\circ} \mathrm{C} / 1 \mathrm{~h}, 120^{\circ} \mathrm{C} / 1 \mathrm{~h}, 150{ }^{\circ} \mathrm{C} / 1 \mathrm{~h}, 180^{\circ} \mathrm{C} / 1 \mathrm{~h}, 250{ }^{\circ} \mathrm{C} / 1 \mathrm{~h}$, and $300{ }^{\circ} \mathrm{C} / 1 \mathrm{~h}$, respectively. Then, the quartz wafer was immersed into the deionized water to afford the free-standing 6 FPI- 5 film.

The other 6FPI-X films, including 6FPI-0, 6FPI-10, 6FPI-15, 6FPI-20, and 6FPI-25 were prepared on the basis of the similar procedures mentioned above.

\section{Results and Discussion}

\subsection{FPI-X Composite Films Preparation}

In order to develop high-performance polymer substrates with both excellent $\mathrm{AO}$ resistance and low- $D_{\mathrm{k}}$ values for potential applications as antenna components for LEO spacecraft, a series of PI nanocomposite polymers were synthesized according to the synthesis routes shown in Figure 2. The PI matrix was based on the fluoro-containing PI (6FDA-BDAF) system, which has been well known as aerospace-class PI materials servicing in the geosynchronous earth orbit (GEO) spacecraft due to the excellent combined properties, including excellent ultraviolet-light resistance, good thermal stability, high optical transparency, and good mechanical and dielectric properties [28]. Especially, the PI (6FDA-BDAF) matrix has been proven to exhibit low- $D_{\mathrm{k}}$ and low- $D_{\mathrm{f}}$ features in the wide frequency range [29]. Thus, the system might be one of the best candidates for antenna substrate applications. However, the PI system was highly sensitive to AO exposure and might lose the original valuable properties in LEO environments. The introduction of TSP-POSS into the matrix might be an effective method to enhance the AO-resistant properties of the pristine polymer. TSP-POSS has been widely used for the improvements of AO resistance of common Kapton ${ }^{\circledR}$ film [30]. The polar trisilanol groups in TSP-POSS could efficiently increase the miscibility of the compounds with the polar poly(amic acid) (PAA) matrix. This made the TSP-POSS a good candidate as additives for developing 
high-performance nanocomposites in which the nano-level uniform dispersion and optical transparency were especially concerned. In the current research, both the PI (6FDA-BDAF) matrix and the TSP-POSS additives are thought to be good candidates for developing antenna substrates with potential applications in LEO.
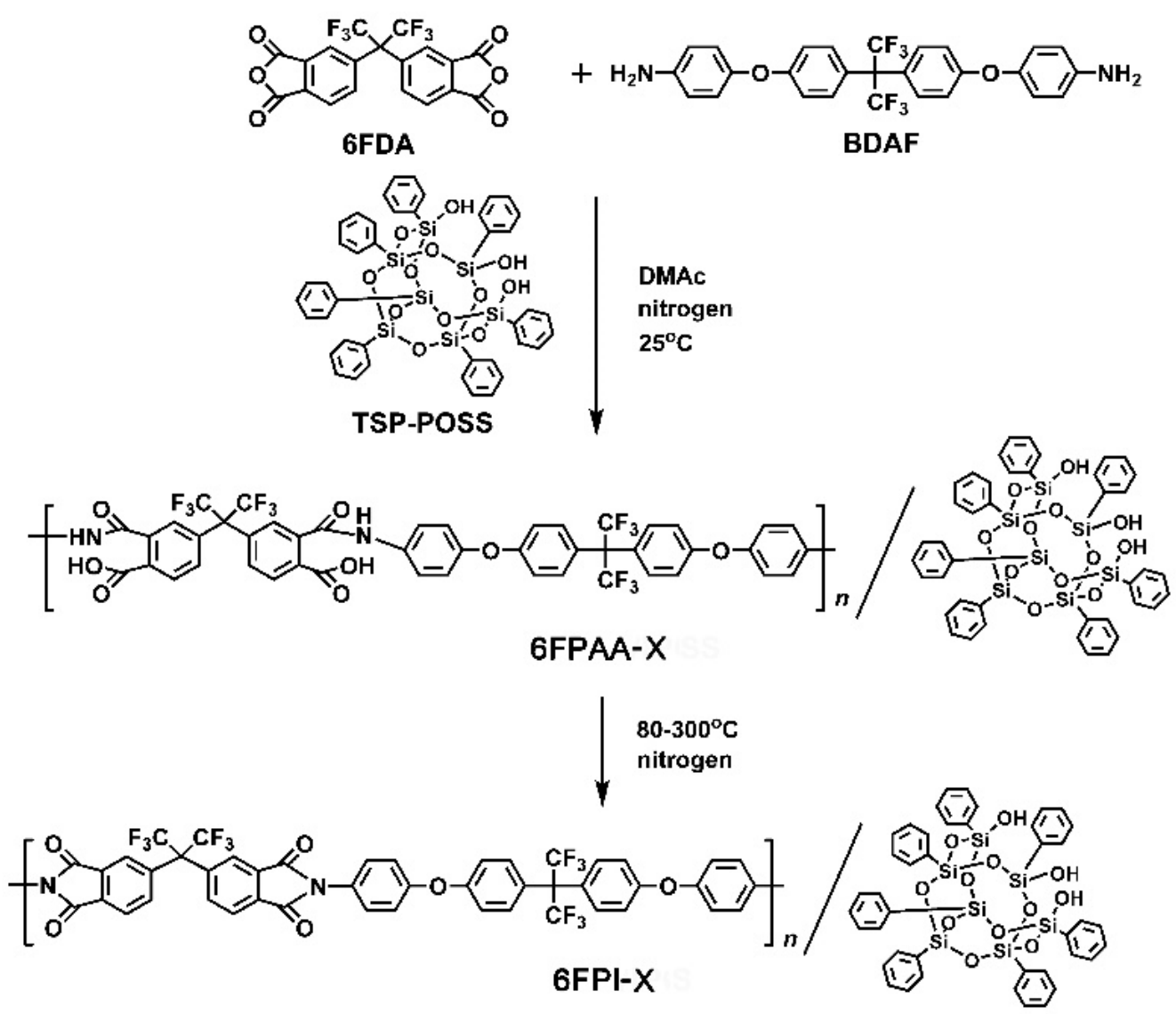

Figure 2. Synthesis of 6FPAA-X solutions and preparation of 6FPI-X composite films.

The TSP-POSS additives exhibited good miscibility with both the PAA and PI matrix, which could be found in Figure 3, in which the appearances of the 6FPAA-X PAA solutions (Figure 3a) and the typical 6FPI-25 film (Figure 3b) were presented. It can be visually observed that the PI composite films with the TSP-POSS loading amounts as high as $25 \mathrm{wt} \%$ could still maintain good optical transparency. This is mainly attributed to the nanolevel miscibility between the matrix and the additives. No obvious particle accumulation and phase separation occurred between the continuous phase (PI) and the disperse phase (TSP-POSS). 
(a)

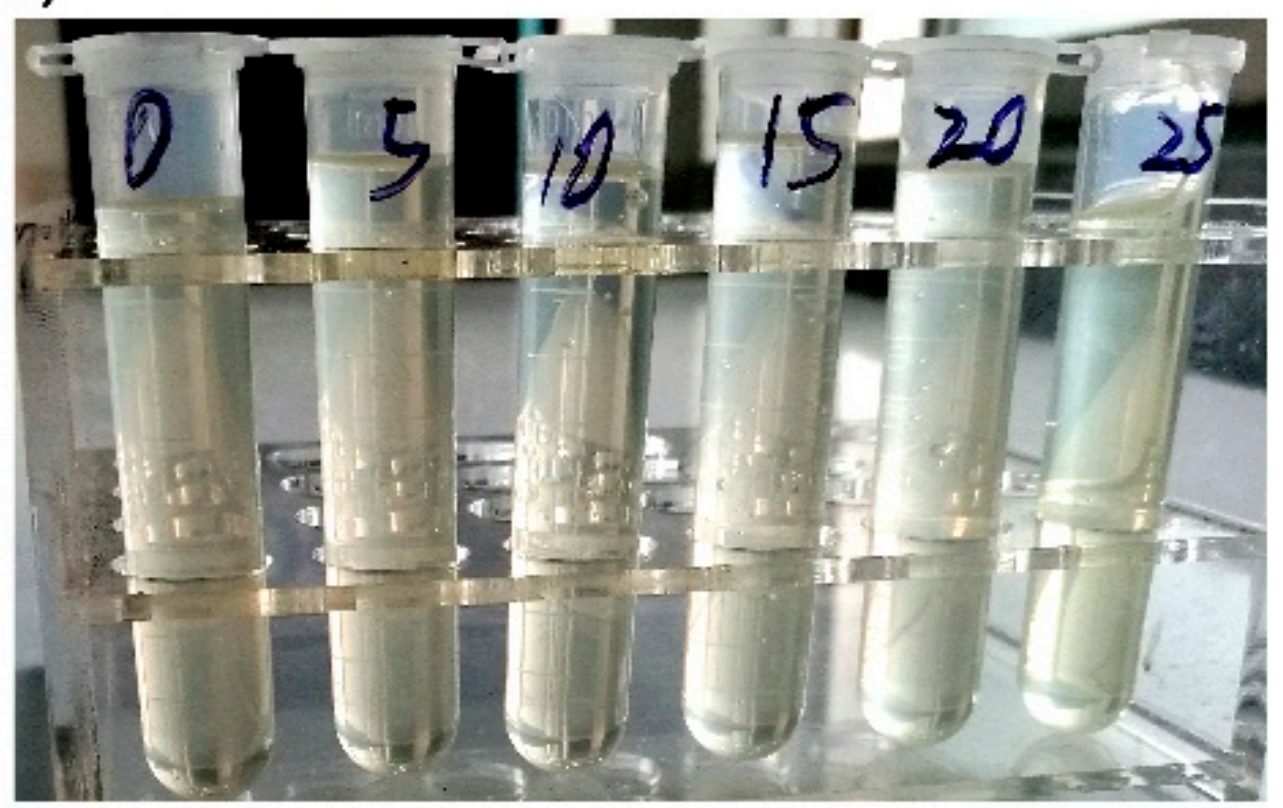

(b)

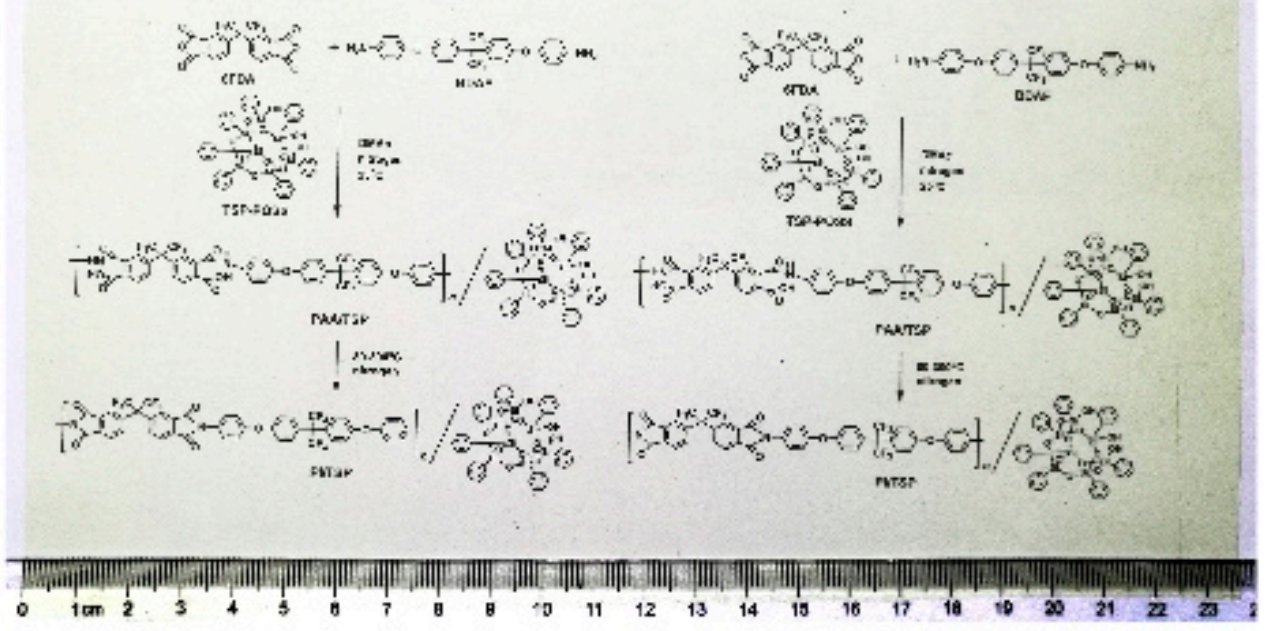

Figure 3. Appearance of polymers. (a) 6FPAA-X solutions (from left to right: 6FPAA-0, 5, 10, 15, 20, and 25); (b) 6FPI-25 composite film.

The chemical structures of the PI films were confirmed by the ATR-FTIR measurements, as shown in Figure 4. All the polymer systems exhibited similar absorption behaviors in the spectra due to the similar structural compositions. For example, the characteristic absorptions of imide groups, including the asymmetrical and symmetrical stretching vibration of $\mathrm{C}=\mathrm{O}$ in imides at about $1786 \mathrm{~cm}^{-1}$ and $1721 \mathrm{~cm}^{-1}$, respectively, and stretching vibration of C-N in imides at about $1375 \mathrm{~cm}^{-1}$ were all clearly detected for all of the samples. The differences among the spectra mainly came from the characteristic absorptions of Si-O-Si structure in TSP-POSS additives at $1132 \mathrm{~cm}^{-1}$. It was not observed in the spectrum of 6FPI-0 without TSP-POSS filler. However, it was clearly found in the spectra of the composite films. Meanwhile, with the increase of TSP-POSS additives, the Si-O-Si absorption peak strength gradually increased, indicating that POSS fillers were successfully added into the polymers. 


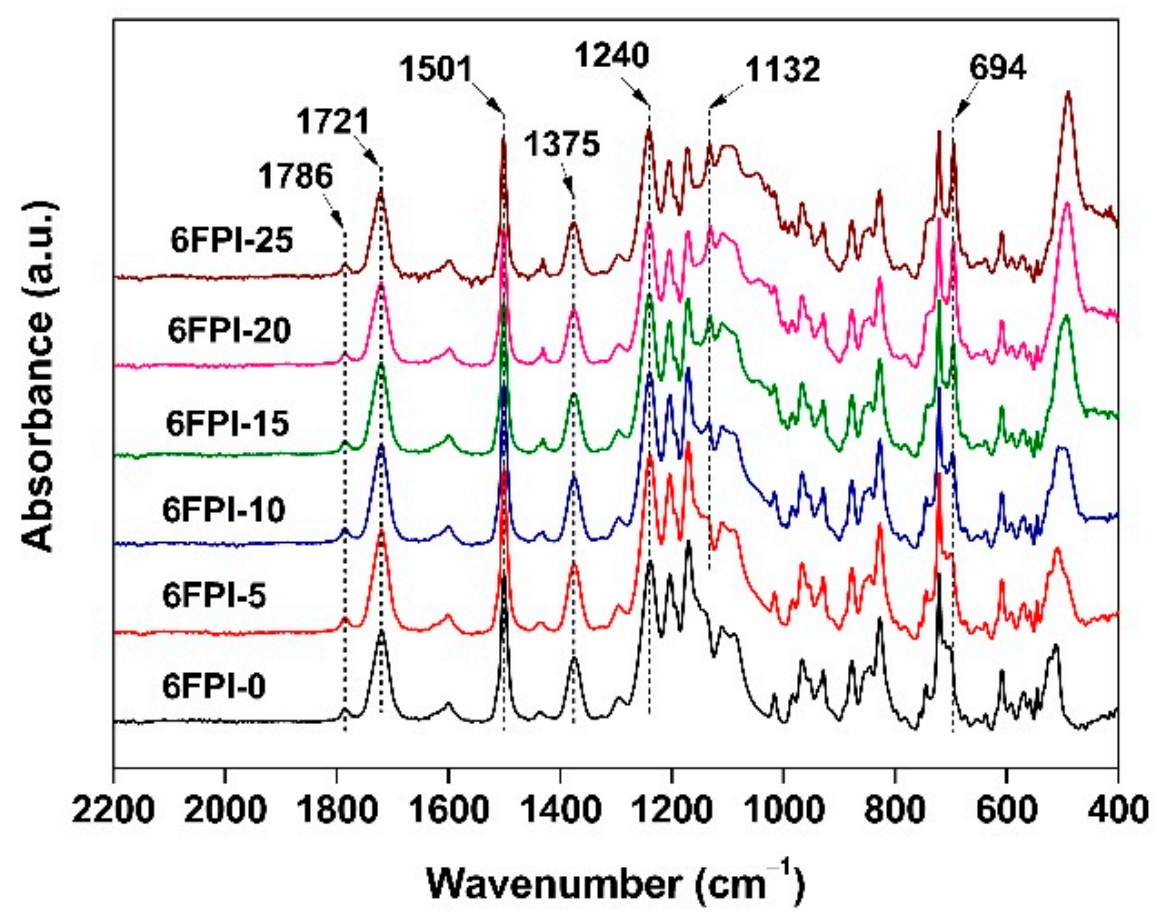

Figure 4. ATR-FTIR spectra of 6FPI-POSS composite films.

The XRD plots of the PI films together with the TSP-POSS additive were shown in Figure 5. TSP-POSS exhibited obvious crystalline features with scattering angles in the range of $10^{\circ}$ to $30^{\circ}$. However, only blunt absorption peaks instead of sharp ones for TSP-POSS were observed in the spectra of the PI composite films, indicating the good compatibility between TSP-POSS and PI matrix.

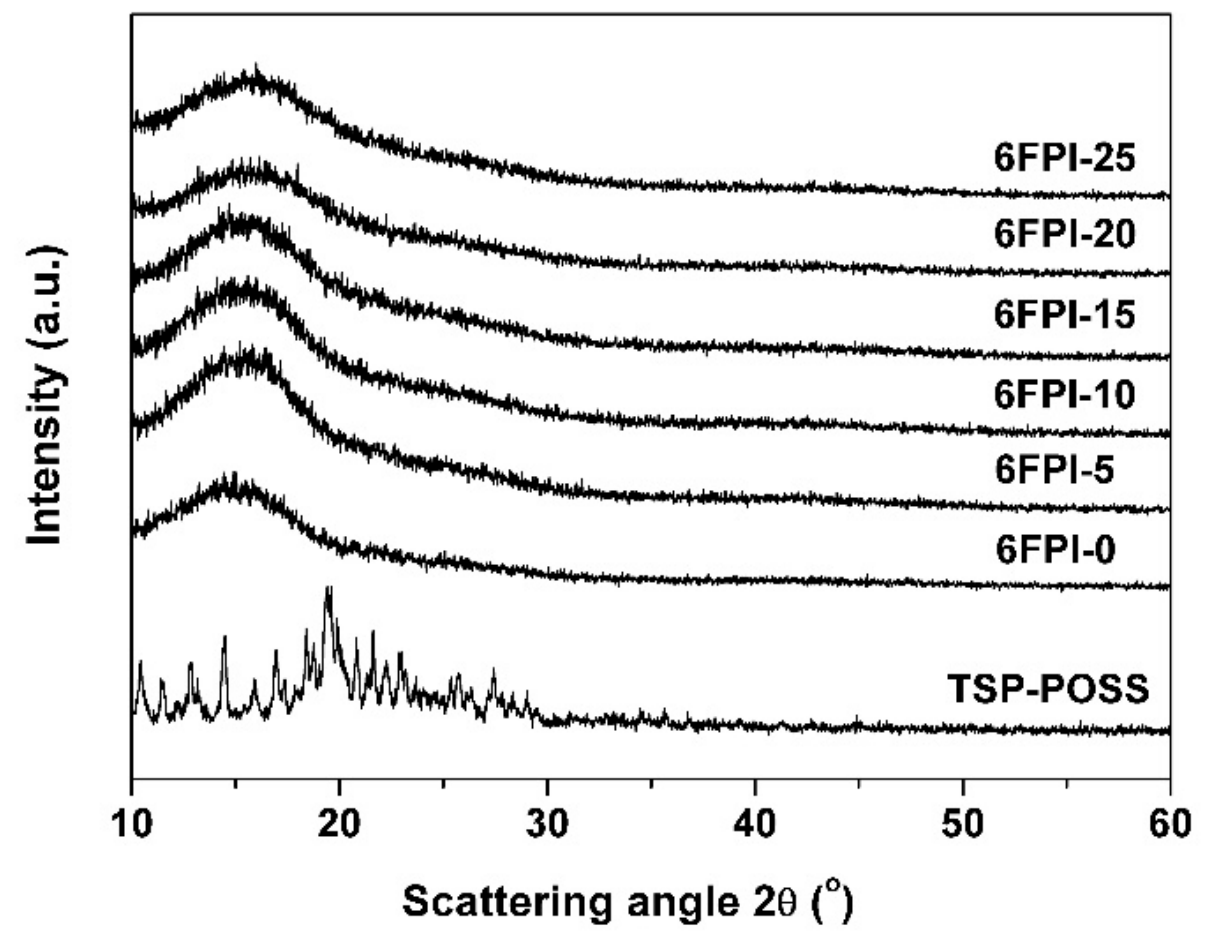

Figure 5. XRD plots of 6FPI-POSS composite films. 
The XPS spectra of the PI films shown in Figure 6 also proved the successful incorporation of the TSP-POSS additives into the PI matrix. This could be confirmed from the intensity of the Si2p absorptions in the spectra. For the pristine 6FPI-0, no Si2p absorptions were observed. However, they could be detected in the spectra of the PI composite films (6FPI-5. 6FPI-10, 6FPI-15, 6FPI-20, and 6FPI-25). Meanwhile, with the amounts of the TSP-POSS in the composite films increased, the strength of the Si2p absorption peaks gradually increased. The characteristic absorptions of C1s, N1s, O1s, and F1s were detected for all of the PI samples.

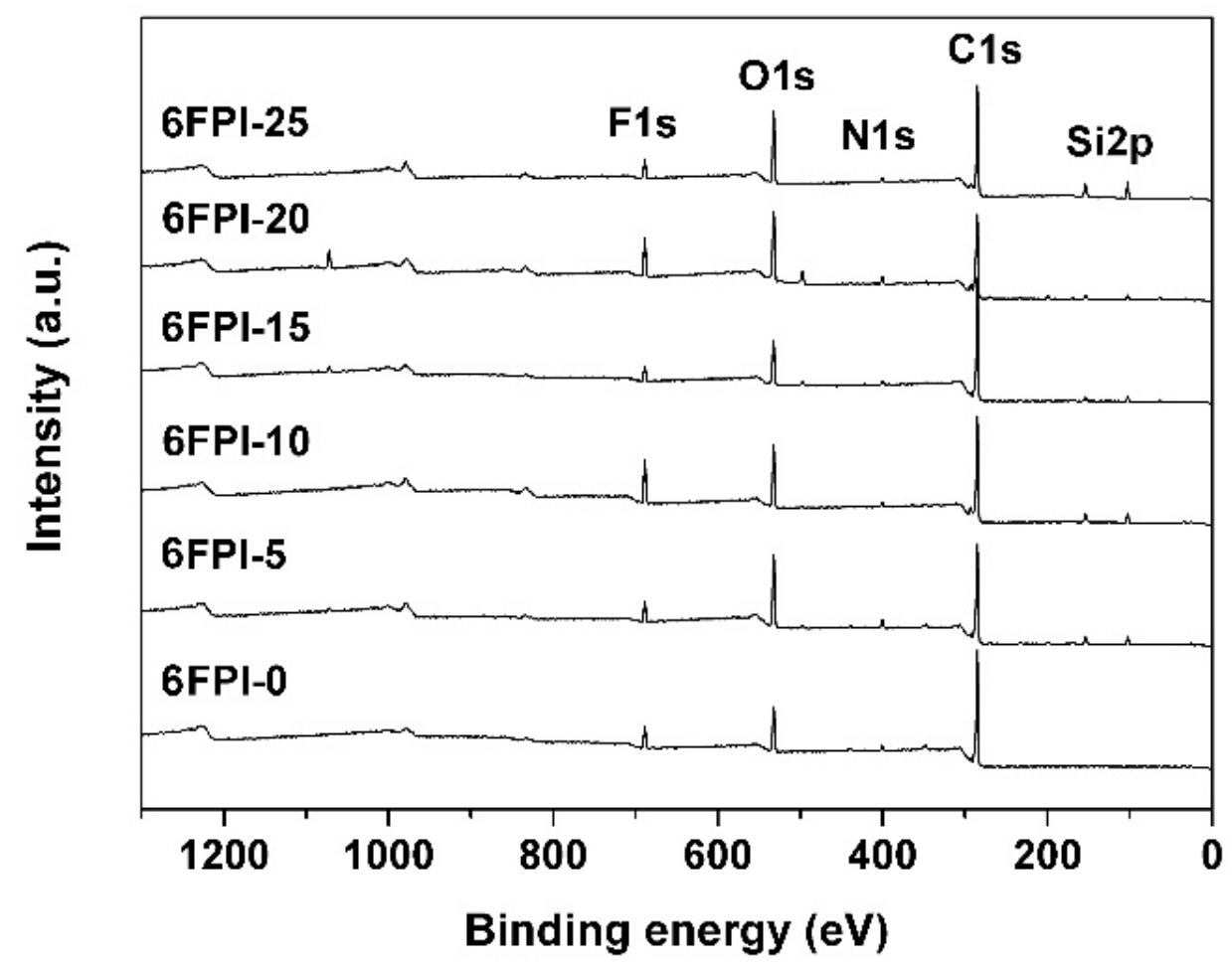

Figure 6. XPS spectra of 6FPI-POSS composite films.

The surface morphology of the PI films was measured by AFM measurements and the obtained images were shown in Figure 7 , together with the average roughness $\left(R_{\mathrm{a}}\right)$ and the root mean square roughness $\left(R_{\mathrm{q}}\right)$ of the PI films. It can be observed that the pristine 6FPI-0 film showed low roughness with the $R_{\mathrm{a}}$ and $R_{\mathrm{q}}$ values of $3.81 \mathrm{~nm}$ and $5.09 \mathrm{~nm}$, respectively. The incorporation of TSP-POSS additives slightly increased the roughness of the PI films. For example, the $R_{\mathrm{a}}$ values of the composite films increased from the original $3.81 \mathrm{~nm}$ for 6FPI-0 to $13.9 \mathrm{~nm}$ for 6FPI-5. Then, the $R_{\mathrm{a}}$ values of the composite films decreased to the level below $10 \mathrm{~nm}$ with the increase of the contents of TSP-POSS additives. This changing trend indicated that the distribution of TSP-POSS additives in the PI composite films tended to be uniform when the loading amounts reached over $5 \mathrm{wt} \%$ in the composite films.

All the characterization results mentioned above proved the uniform dispersion of the TSP-POSS additives into the PI matrix. The original optical transparency of the pristine 6FPI-0 was visually maintained. The influence of the TSP-POSS additives on the other properties of the derived PI composite films will be further studied. 
(a)

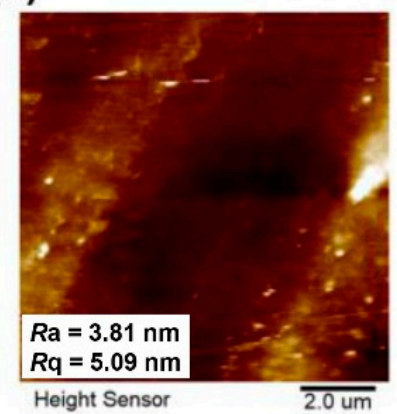

(d)

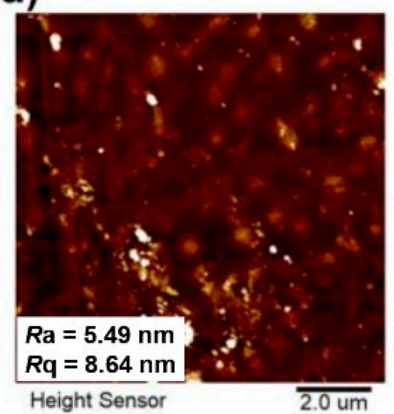

(b)

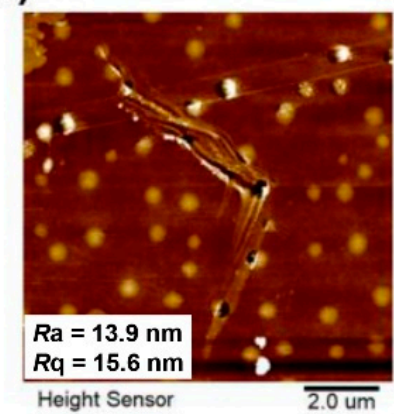

(e)

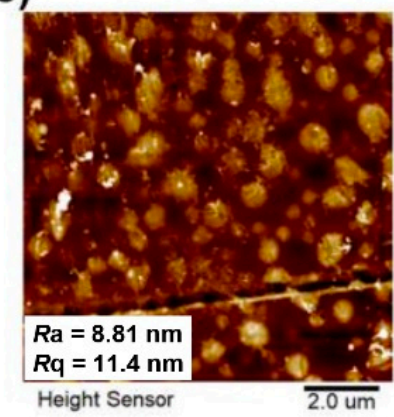

(c)

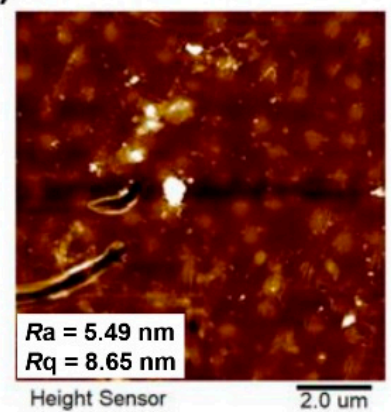

(f)

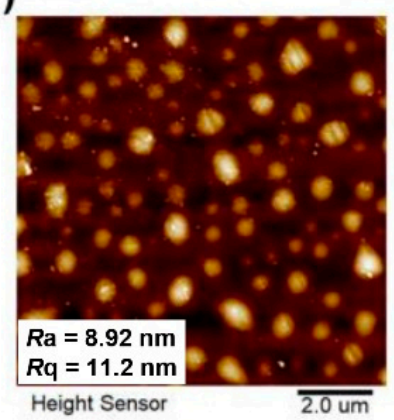

Figure 7. AFM images of 6FPI-POSS composite films with the surface roughness values. (a) 6FPI-0; (b) 6FPI-5; (c) 6FPI-10; (d) 6FPI-15; (e) 6FPI-20; (f) 6FPI-25.

\subsection{Optical and Dielectric Properties}

The influence of the incorporation of the TSP-POSS additives on the optical properties of the PI composite films was quantitatively investigated by UV-Vis, refractive indices, and CIE Lab optical parameters measurements, respectively. The obtained optical data are summarized in Table 2. The UV-Vis spectra of the PI films are shown in Figure 8. It can be seen that the incorporation of TSP-POSS apparently increased the optical transparency of the composite films. For example, the pristine 6FPI-0 film exhibited the cutoff wavelength $\left(\lambda_{\text {cut }}\right)$ of $331 \mathrm{~nm}$ and the transmittance at the wavelength of $450 \mathrm{~nm}\left(T_{450}\right)$ of $82.8 \%$ at the thickness of $25 \mu \mathrm{m}$, respectively. However, for the PI composite films, these optical parameters became better with the incorporation of the TSP-POSS fillers. 6FPI-25 showed a $\lambda_{\text {cut }}$ value of $292 \mathrm{~nm}$, which was $39 \mathrm{~nm}$ lower than that of the 6 FPI- 0 film. The $T_{450}$ value of the 6 FPI-25 film (84.7\%) was also higher than the 6FPI-0 film. This phenomenon might be due to the excellent dispersion of the TSP-POSS additive into the PI matrix. The bulky and cage-like molecular structures of TSP-POSS fillers apparently decreased the molecular chain packing densities in the PI composite films, thus facilitating the penetration of visible light. It is worthy of notice that even the high loading of TSP-POSS up to $25 \mathrm{wt} \%$ did not deteriorate the optical transmittance of the PI composite films. This is quite beneficial for developing high-performance inorganic/organic hybrid composite films with tailored optical properties.

The refractive indices $\left(n_{\mathrm{AV}}\right)$ of the PI films were measured with the prism coupler and the data were tabulated in Table 2. The influence of TSP-POSS additives on the optical properties of the PI composite films could also be deduced from the changing trends of the $n_{\mathrm{AV}}$ values of the films. Although 6FPI-0 and 6FPI-25 films showed very close $n_{\mathrm{AV}}$ values, the $n_{\mathrm{AV}}$ values of the PI composite films first increased with the increasing loading of TSP-POSS from 0 to $10 \mathrm{wt} \%$ in the composite films. Then, the $n_{\mathrm{AV}}$ values of the PI composite films began to decrease when the loading of TSP-POSS was higher than $10 \mathrm{wt} \%$. The -OH groups in TSP-POSS possessed high molar refraction, while the cage-type silsesquioxane groups showed high molar volume. Therefore, when the TSP-POSS content was low $(<10 \mathrm{wt} \%)$, the refractive indices of the composite films increased slightly with the presence of the $-\mathrm{OH}$ structure; however, when the TSP-POSS content was high, the 
cage-type silsesquioxane groups gradually played a predominant role and reduced the refractive indices of the composite films.

Table 2. Optical and dielectric properties of 6FPI-POSS composite films.

\begin{tabular}{|c|c|c|c|c|c|c|c|c|c|}
\hline Samples & $\begin{array}{l}\lambda_{\text {cut }} 1 \\
(\mathrm{~nm})\end{array}$ & $\begin{array}{c}T_{450}{ }^{2} \\
(\%)\end{array}$ & $\begin{array}{c}T_{450 \mathrm{AO}}{ }^{2} \\
(\%)\end{array}$ & $n_{\mathrm{AV}}^{4}$ & $\Delta n^{4}$ & $b^{* 3}$ & $\begin{array}{c}\text { Haze } \\
(\%)\end{array}$ & $D_{\mathrm{k}}^{5}$ & $D_{\mathrm{f}}^{5}$ \\
\hline 6FPI-0 & 331 & 82.8 & 65.2 & 1.5792 & 0.0106 & 4.40 & 2.05 & 2.84 & 0.009 \\
\hline 6FPI-5 & 326 & 83.3 & 0.8 & 1.5820 & 0.0110 & 5.71 & 2.48 & 2.76 & 0.011 \\
\hline 6FPI-10 & 309 & 84.8 & 1.9 & 1.5822 & 0.0093 & 5.78 & 3.27 & 2.69 & 0.012 \\
\hline 6FPI-15 & 309 & 83.1 & 10.9 & 1.5806 & 0.0084 & 6.28 & 4.44 & 2.63 & 0.012 \\
\hline 6FPI-20 & 294 & 83.2 & 25.7 & 1.5797 & 0.0110 & 3.83 & 4.70 & 2.58 & 0.009 \\
\hline 6FPI-25 & 292 & 84.7 & 37.1 & 1.5765 & 0.0091 & 3.80 & 5.14 & 2.52 & 0.010 \\
\hline
\end{tabular}

${ }^{1}$ Cutoff wavelength. ${ }^{2} T_{450}, T_{450 \mathrm{AO}}$ : Transmittance at $450 \mathrm{~nm}$ at a thickness of $25 \mu \mathrm{m}$ before and after AO erosion; ${ }^{3}$ yellow index determined by $b^{*} .{ }^{4} n_{\mathrm{AV}}$ : average refractive index; $\Delta n$ : birefringence. ${ }^{5} D_{k}$ : dielectric constant measured at $1 \mathrm{MHz} ; D_{f}$ : dielectric loss factor measured at $1 \mathrm{MHz}$.

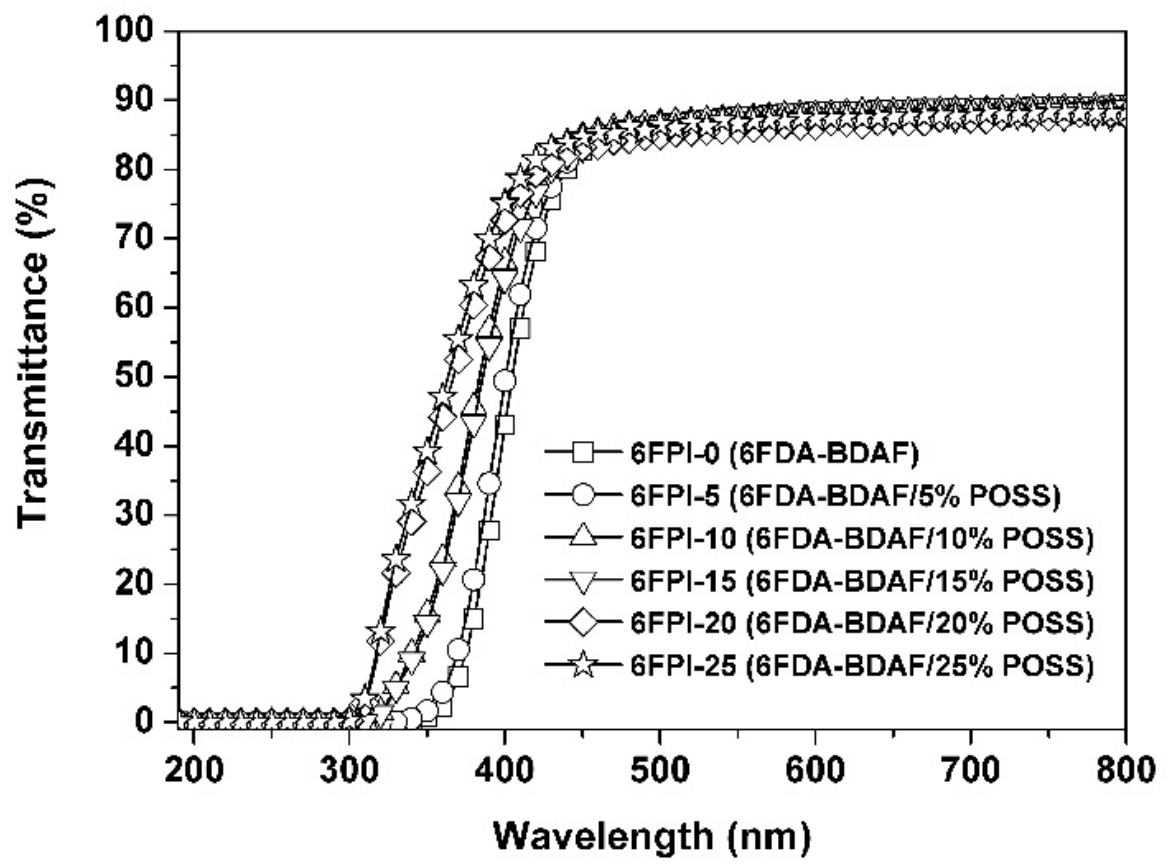

Figure 8. UV-Vis spectra of 6FPI-POSS composite films.

The three-dimension (3D) plots of CIE Lab parameters of the PI films were shown in Figure 9, and the corresponding data are summarized in Table 2. The pristine 6FPI-0 film showed low color parameters with the lightness $\left(L^{*}\right)$ of 95.78 , the yellow indices $\left(b^{*}\right)$ of 4.40 , and the haze of $2.05 \%$. With the increase of the contents of TSP-POSS additives, the $L^{*}$ values of the films decreased first and then increased, while the $b^{*}$ values of the films showed a trend of increasing first and then decreasing. The -OH groups in TSP-POSS were sensitive to the high-temperature oxidative environments during the fabrication of PI films from 80 to $300{ }^{\circ} \mathrm{C}$. Therefore, when the TSP-POSS additives were incorporated into the PI matrix at low contents, the optical parameters of the composite films slightly deteriorated. However, when the contents of TSP-POSS additives reached a high level (>15 wt\%), a partly continuous TSP-POSS phase gradually formed in the composite films. This is beneficial for improving the lightness and decreasing the yellow indices of the composite films. As for the haze values of the PI films, they increased with the gradual increase of the contents of TSP-POSS additives. 6FPI-25 exhibited the highest haze value of $5.14 \%$ in the samples, which was apparently higher than that of the pristine 6FPI-0 (haze $=2.05 \%$ ). This suggested that although very uniform dispersion was formed between 
the PI matrix and the TSP-POSS additives, microscopic aggregation might occur for the TSP-POSS fillers, especially at a higher content.

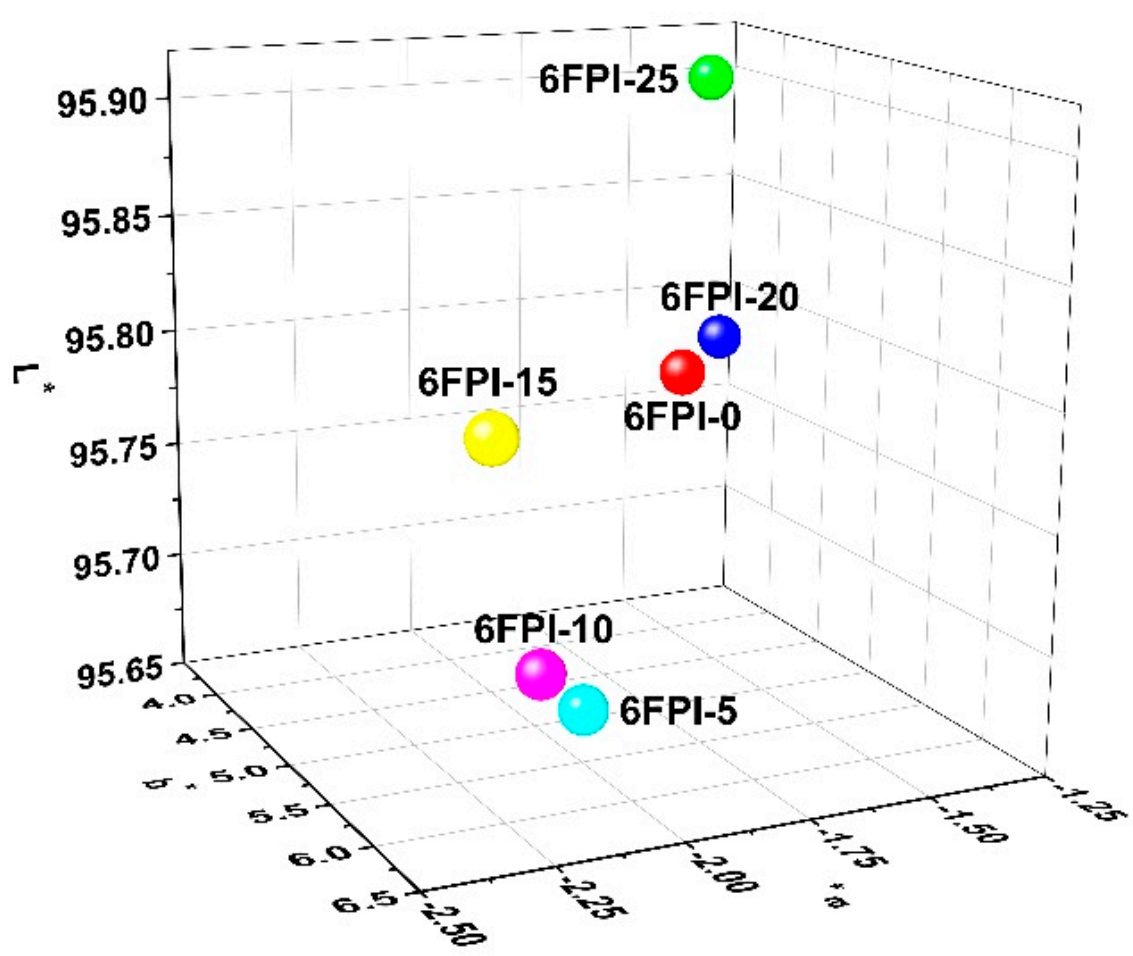

Figure 9. CIE Lab parameters of 6FPI-POSS composite films.

Although the incorporation of TSP-POSS showed some positive and negative effects on the optical properties of the PI composite films, the optical properties of the polymers were not the main concerns in the current research. Figure 10 shows the curve of the dielectric constants of the PI films as a function of frequency. All the PI films showed stable $D_{\mathrm{k}}$ values in the frequency range from $10^{3}$ to $10^{6} \mathrm{~Hz}$. The $6 \mathrm{FPI}-0$ film, an intrinsically low- $D_{\mathrm{k}}$ PI [28], showed the $D_{\mathrm{k}}$ value of 2.84 at $1 \mathrm{MHz}$ and the $D_{\mathrm{f}}$ value of 0.009 . The addition of TSP-POSS additives apparently reduced the $D_{\mathrm{k}}$ values of PI composite films, while the $D_{\mathrm{f}}$ values maintained the same level. With the increase of the TSP-POSS contents, the $D_{\mathrm{k}}$ values of the PI films decreased from $2.84(1 \mathrm{MHz})$ of 6 FPI-0 to $2.52(1 \mathrm{MHz})$ of 6FPI-25, while the $D_{\mathrm{f}}$ values correspondingly changed from $0.009(1 \mathrm{MHz})$ to $0.011(1 \mathrm{MHz})$ According to the Clausius-Mossotti equation, the increase of the internal space of materials can reduce the dielectric constant [31]. Herein, the introduction of TSP-POSS additives with a large bulky structure can break the tight packing of PI molecular chains, thus reducing the dielectric constant of PI composite films. The low- $D_{\mathrm{k}}$ feature of the current PI composite films is mainly attributed to the synergistic effects of the bulky hexafluoroisopropylene groups in PI matrix and the bulky silsesquioxane groups in TSP-POSS additives. The low $D_{\mathrm{k}}$ value of 2.52 at $1 \mathrm{MHz}$ makes the 6FPI-25 a good candidate as high-performance substrates for spacecraft antenna. 


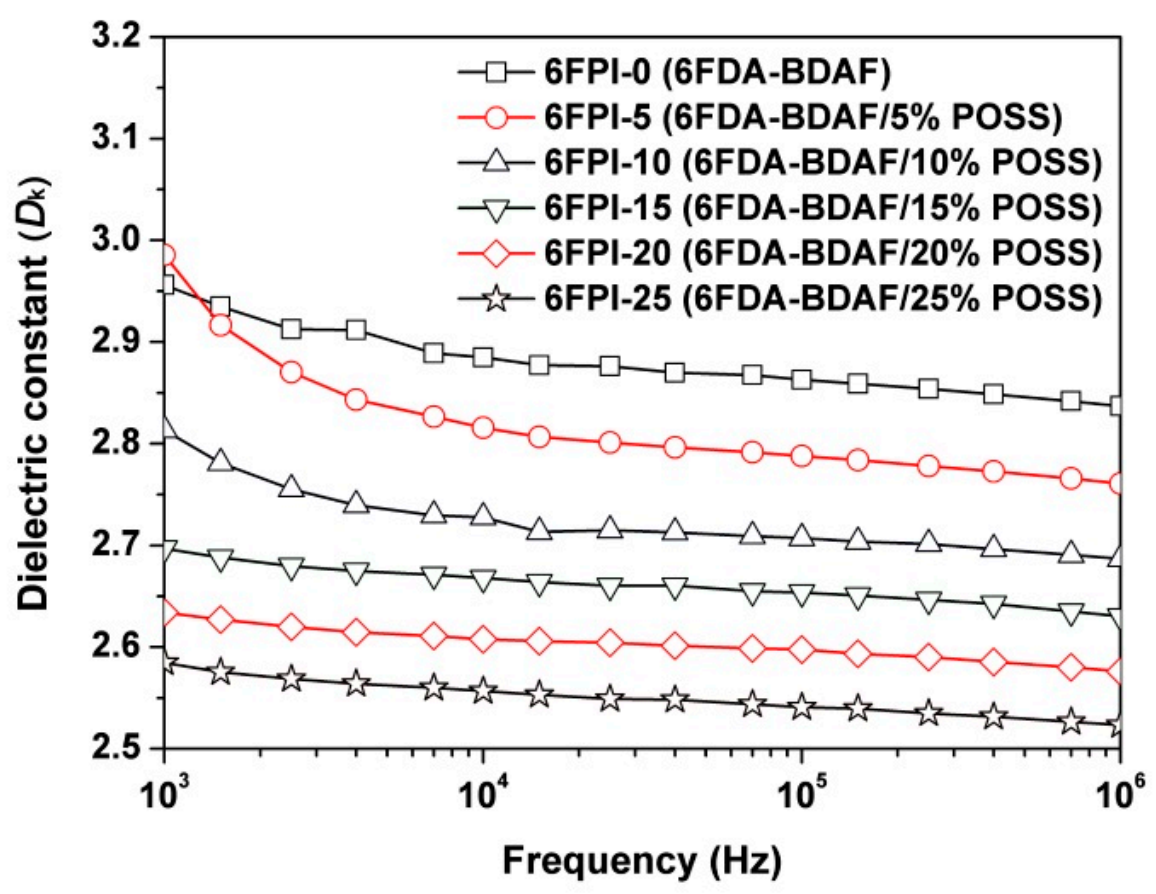

Figure 10. Dielectric parameters of 6FPI-POSS composite films.

\subsection{Thermal Properties}

The influence of the incorporation of TSP-POSS on the thermal stability of the PI composite films was studied by TGA, DSC, and TMA measurements, respectively, and the data are tabulated in Table 3. The TGA curves of the PI films measured in nitrogen environments were shown in Figure 11. All the PI films maintained their initial weights when the temperature was over $450{ }^{\circ} \mathrm{C}$ and the $T_{5 \%}$ values were recorded in the range of 494-520 ${ }^{\circ} \mathrm{C}$. The pure TSP-POSS additives exhibited good thermal stability with the $T_{5 \%}$ values over $360{ }^{\circ} \mathrm{C}$ in nitrogen [32], which endowed the PI composite films with good thermal stability. The PI films left $45.3 \sim 53.8 \%$ of their original weights at $760{ }^{\circ} \mathrm{C}$. The $R_{\mathrm{w} 760}$ values of the PI films decreased with the order of 6FPI-0 (53.8\%) $>6$ FPI-5 (53.6\%) $>$ 6FPI-10 $(48.4 \%)>6$ FPI-15 $(48.1 \%)>6$ FPI-20 $(47.4 \%)>6$ FPI-25 $(45.3 \%)$. This trend is quite different from the thermal decomposition behaviors of conventional POSS/polymer composite films, which is peculiar to the POSS combined fluoro-containing systems. This phenomenon is mainly attributed to the releasing of gaseous fluorine-silicon compounds derived from the reaction of decomposed fluoro species and the silicon elements at elevated temperatures [12].

Table 3. Thermal properties of the 6FPI/POSS composite films.

\begin{tabular}{cccccc}
\hline Samples & $\begin{array}{c}\boldsymbol{T}_{\mathbf{g}} \mathbf{1} \\
\left({ }^{\circ} \mathbf{C}\right)\end{array}$ & $\begin{array}{c}\boldsymbol{T}_{\mathbf{5 \%}} \mathbf{1} \\
\left({ }^{\circ} \mathbf{C}\right)\end{array}$ & $\begin{array}{c}\boldsymbol{T}_{\mathbf{1 0 \%}} \mathbf{1} \\
\left({ }^{\circ} \mathbf{C}\right)\end{array}$ & $\begin{array}{c}\boldsymbol{R}_{\mathbf{w 7 6 0}} \mathbf{1} \\
\mathbf{( \% )}\end{array}$ & $\begin{array}{c}\mathbf{C T E}^{\mathbf{1}} \\
(\mathbf{1 0}\end{array}$ \\
\hline 6FPI-0 & 256.2 & 520 & 533 & 53.8 & 62.3 \\
6FPI-5 & 258.8 & 509 & 525 & 53.6 & 64.8 \\
6FPI-10 & 259.7 & 494 & 517 & 48.4 & 66.4 \\
6FPI-15 & 259.3 & 497 & 517 & 48.1 & 69.4 \\
6FPI-20 & 259.4 & 500 & 517 & 47.4 & 69.6 \\
6FPI-25 & 260.2 & 494 & 512 & 45.3 & 72.4 \\
\hline
\end{tabular}

${ }^{1} T_{\mathrm{g}}$ : Glass transition temperatures determined by DSC measurements; $T_{5 \%}, T_{10 \%}: 5 \%$ and $10 \%$ weight loss temperature, respectively; $R_{\mathrm{w} 760}$ : residual weight ratio at $760{ }^{\circ} \mathrm{C}$; CTE: coefficient of linear thermal expansion recorded between $50-200{ }^{\circ} \mathrm{C}$. 


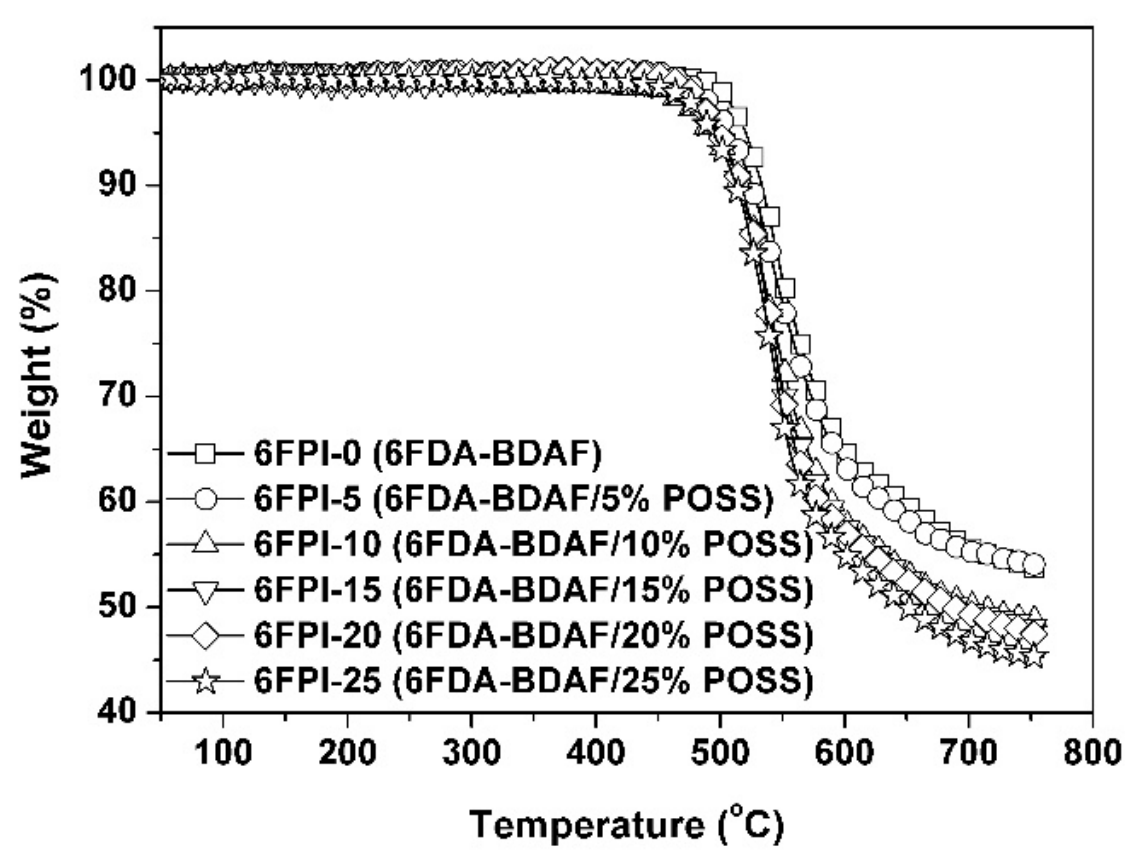

Figure 11. TGA curves 6FPI/POSS composite films under nitrogen flow.

The DSC diagram of PI films was shown in Figure 12. It can be seen from the figure that the incorporation of TSP-POSS has little effect on the $T_{\mathrm{g}}$ values of PI films. The $T_{\mathrm{g}}$ value of the pristine 6FPI-0 film was very close to those of the PI composite films. On one hand, the TSP-POSS possessed bulky molecular chains, which were not easy to move at elevated temperatures. On the other hand, the TSP-POSS additives might not have a strong interaction with the PI matrix due to the absence of active groups in the PI matrix. These factors lead to that TSP-POSS additives have little effect on the glass transition behaviors of the PI composite films.

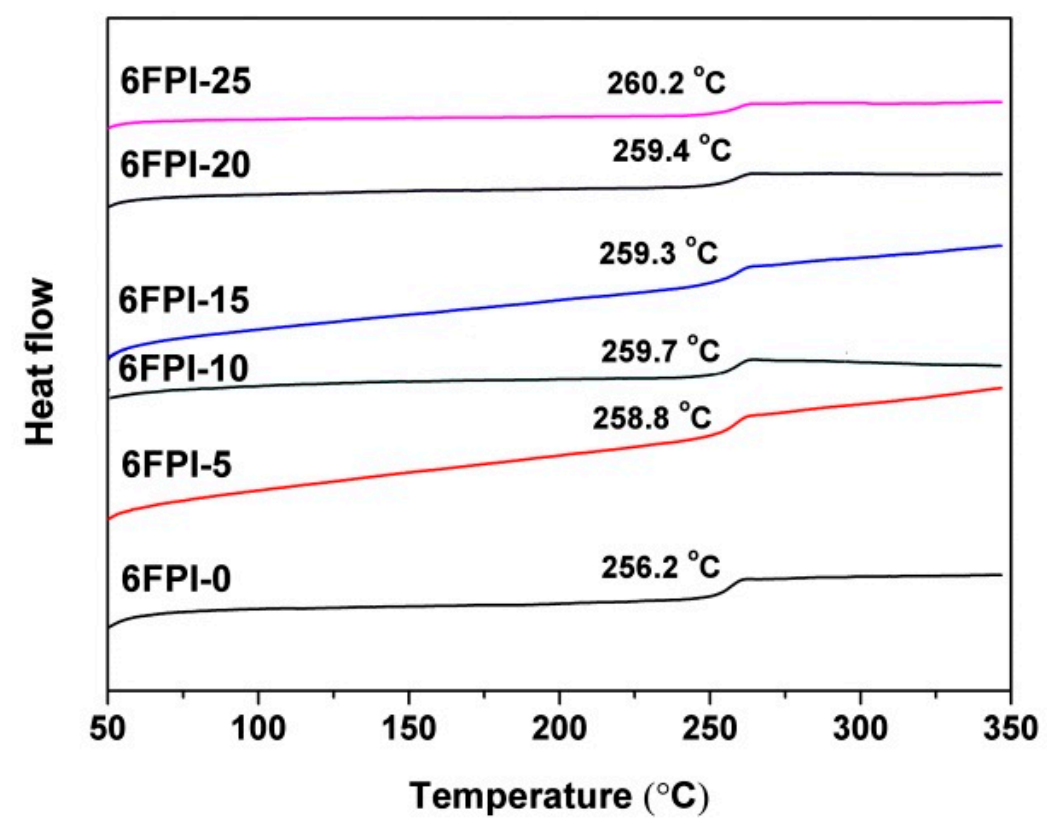

Figure 12. DSC curves 6FPI/POSS composite films under nitrogen flow.

Although the incorporation of TSP-POSS additives into the PI matrix did not bring negative effects on the $T_{\mathrm{g}}$ values of the PI composite films, they deteriorated the hightemperature dimensional stability of the polymers, as could be evidenced by the TMA 
plots of the PI composite films in Figure 13. The pristine 6FPI-0 film itself possessed the CTE value of $62.3 \times 10^{-6} / \mathrm{K}$ due to the presence of flexible hexafluoroisopropylene and ether linkages in the polymer. When the TSP-POSS additives were introduced, the composite films showed further increased CTE values at elevated temperatures. For example, 6FPI-25 exhibited a CTE value of $72.4 \times 10^{-6} / \mathrm{K}$, which was obviously higher than that of the pristine 6FPI-0 film. Apparently, the plasticization effects of the TSP-POSS fillers increased the CTE values of the composite films. The deteriorated high-temperature dimensional stability might be disadvantageous for their applications as substrates for spacecraft antennas. Modification of the high-temperature dimensional stability of the current PI composite films will be investigated in our future work.

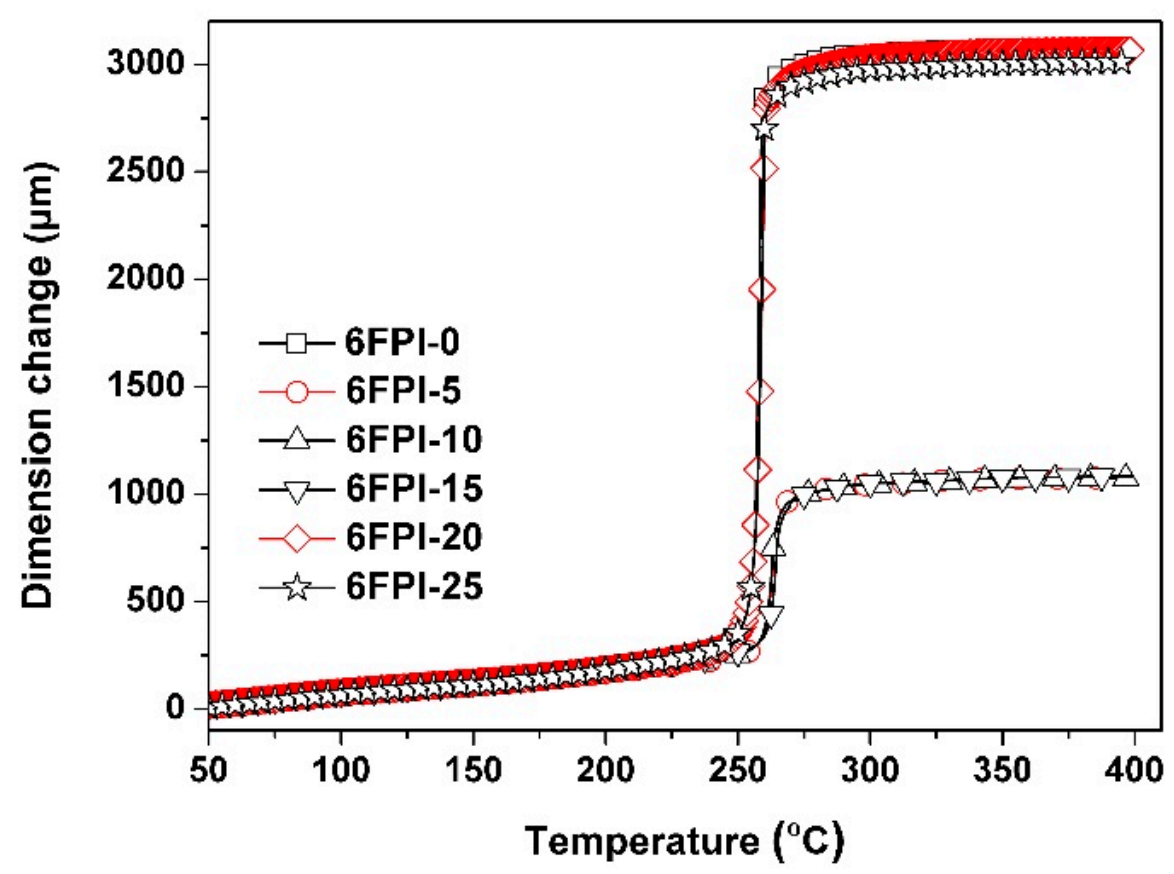

Figure 13. TMA curves 6FPI/POSS composite films at a heating rate of $10^{\circ} \mathrm{C} / \mathrm{min}$ under nitrogen flow.

\subsection{AO Erosion Properties}

The AO erosion behaviors of the PI composite films were evaluated in a ground simulation facility. The actual total AO exposure fluence was $4.02 \times 10^{20}$ atoms $/ \mathrm{cm}^{2}$, which is equivalent to nearly half a year of AO exposure in LEO at the altitude of $500 \mathrm{~km}$ [33]. Kapton ${ }^{\circledR}$ films were used as a reference, whose erosion yield $\left(E_{\mathrm{S}}\right)$ of $3.0 \times 10^{-24} \mathrm{~cm}^{3} /$ atom was taken as a standard. The PI films after AO exposure were named as "6FPI-X-AO", where $\mathrm{X}$ stands for the weight percent of TSP-POSS additives in the composite films. Figure 14 shows the $E_{\mathrm{S}}$ values of the PI films, together with the appearances of the typical 6FPI-0-AO and 6FPI-25-AO. The experimental data for the AO erosion evaluation are listed in Table 4. It could be clearly seen that the $E_{\mathrm{S}}$ values of the PI films apparently decreased with the increase of the TSP-POSS contents in the PI composite films. 6FPI-25 sample with the highest TSP-POSS contents showed the lowest $E_{\mathrm{S}}$ value of $0.40 \times 10^{-24} \mathrm{~cm}^{3} /$ atom, which was nearly an order of magnitude lower than that of Kapton $^{\circledR}$, and also nearly an order of magnitude lower than that of the pristine 6FPI-0 film $\left(E_{\mathrm{S}}=2.60 \times 10^{-24} \mathrm{~cm}^{3}\right.$ /atom). Thus, the incorporation of TSP-POSS additives could efficiently enhance the AO-resistant properties of the PI composite films. 


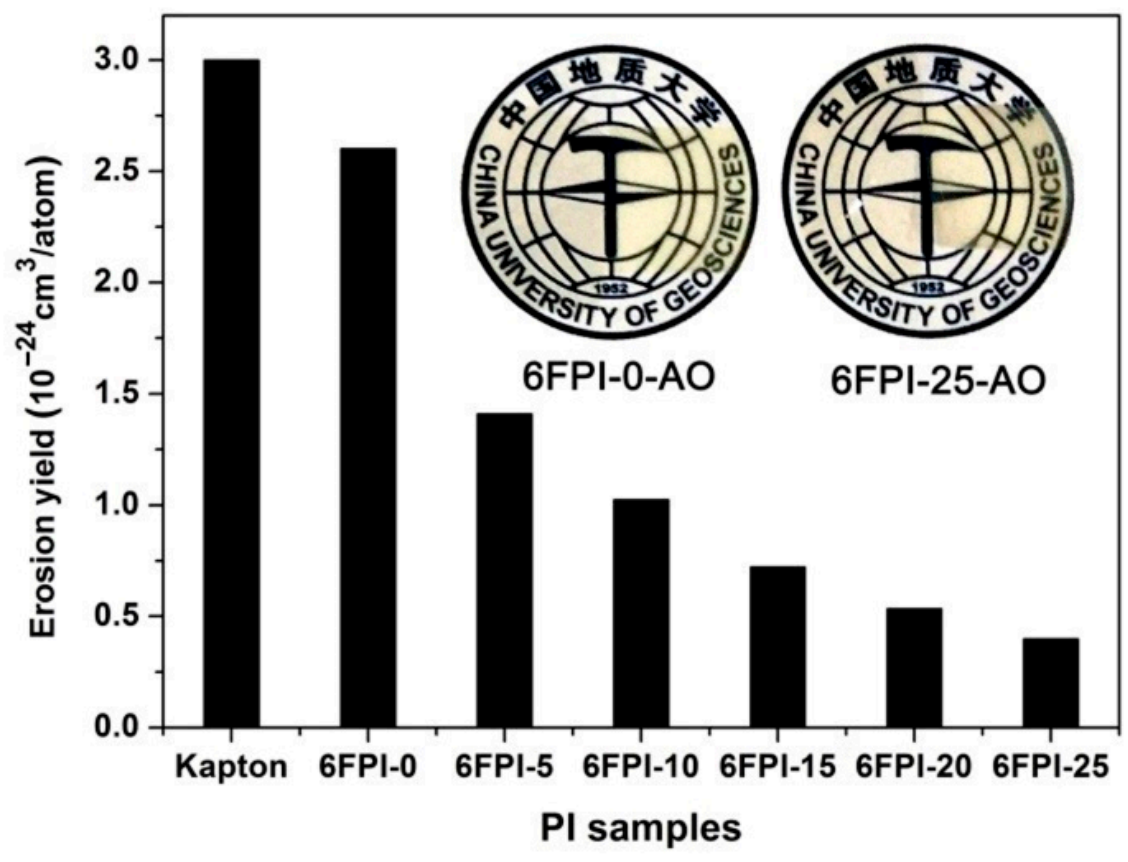

Figure 14. AO erosion yields of the 6FPI-POSS composite films (Insert: Appearance of representative 6FPI-0-AO and 6FPI-25-AO films).

Table 4. AO effects and erosion yields for 6FPI/POSS composite films.

\begin{tabular}{|c|c|c|c|c|c|}
\hline Samples & $\begin{array}{c}\text { TSP-POSS }^{1} \\
(\%)\end{array}$ & $\begin{array}{l}W_{1}^{2} \\
(\mathrm{mg})\end{array}$ & $\begin{array}{l}W_{2}^{2} \\
(\mathrm{mg})\end{array}$ & $\begin{array}{l}\Delta W^{3} \\
(\mathrm{mg})\end{array}$ & $\begin{array}{c}E_{\mathrm{s}}^{4} \\
\left(10^{-24} \mathrm{~cm}^{3} / \text { atom }\right)\end{array}$ \\
\hline 6FPI-0 & 0 & 10.87 & 4.93 & 5.94 & 2.60 \\
\hline 6FPI-5 & 5 & 12.28 & 9.06 & 3.22 & 1.41 \\
\hline 6FPI-10 & 10 & 11.86 & 9.52 & 2.34 & 1.02 \\
\hline 6FPI-15 & 15 & 11.37 & 9.72 & 1.65 & 0.72 \\
\hline 6FPI-20 & 20 & 11.96 & 10.74 & 1.22 & 0.53 \\
\hline 6FPI-25 & 25 & 11.87 & 10.96 & 0.91 & 0.40 \\
\hline Kapton $^{\circledR}$ & - & 30.85 & 24.00 & 6.85 & 3.00 \\
\hline
\end{tabular}

${ }^{1}$ TSP-POSS content in the PI sample; ${ }^{2} W_{1}$ : weight of the sample before irradiation; $W_{2}$ : weight of the sample after irradiation; ${ }^{3}$ weight loss of the sample during irradiation, $\Delta W=W_{1}-W_{2} ;{ }^{4}$ erosion yield.

It could also be observed from Figure 14 that the PI films became opaque after AO exposure. Figure 15 presents the UV-Vis spectra of the AO-exposed 6FPI-X-AO films after the AO exposure with the dose of $4.02 \times 10^{20}$ atoms $/ \mathrm{cm}^{2}$ and the optical transmittance at $450 \mathrm{~nm}$ of the AO-exposed PI films $\left(T_{450 \mathrm{AO}}\right)$ are shown in Table 2 . First, when comparing the $T_{450}$ data of the PI films shown in Figures 8 and 15, an apparent decrease of the optical transparency for the PI films before and after AO exposure could be clearly observed. For example, the $6 \mathrm{FPI}-25$ film showed the $T_{450}$ value of $84.7 \%$, while the $6 \mathrm{FPI}-25-\mathrm{AO}$ film showed a value of $37.1 \%$. This indicated that $\mathrm{AO}$ exposure severely deteriorates the optical properties of PI films. Secondly, the $T_{450 \mathrm{AO}}$ values of $6 \mathrm{FPI}-\mathrm{X}-\mathrm{AO}$ films decreased with the order of 6FPI-0-AO $>6$ FPI-25-AO $>6$ FPI-20-AO $>6$ FPI-15-AO $>6$ FPI-10-AO $>6$ FPI-5-AO, which was different from that of the 6FPI-X films. Thus, for the PI composite films, the influence of the $\mathrm{AO}$ exposure on the deterioration of the optical transparency might be influenced by many factors, which will be discussed below. 


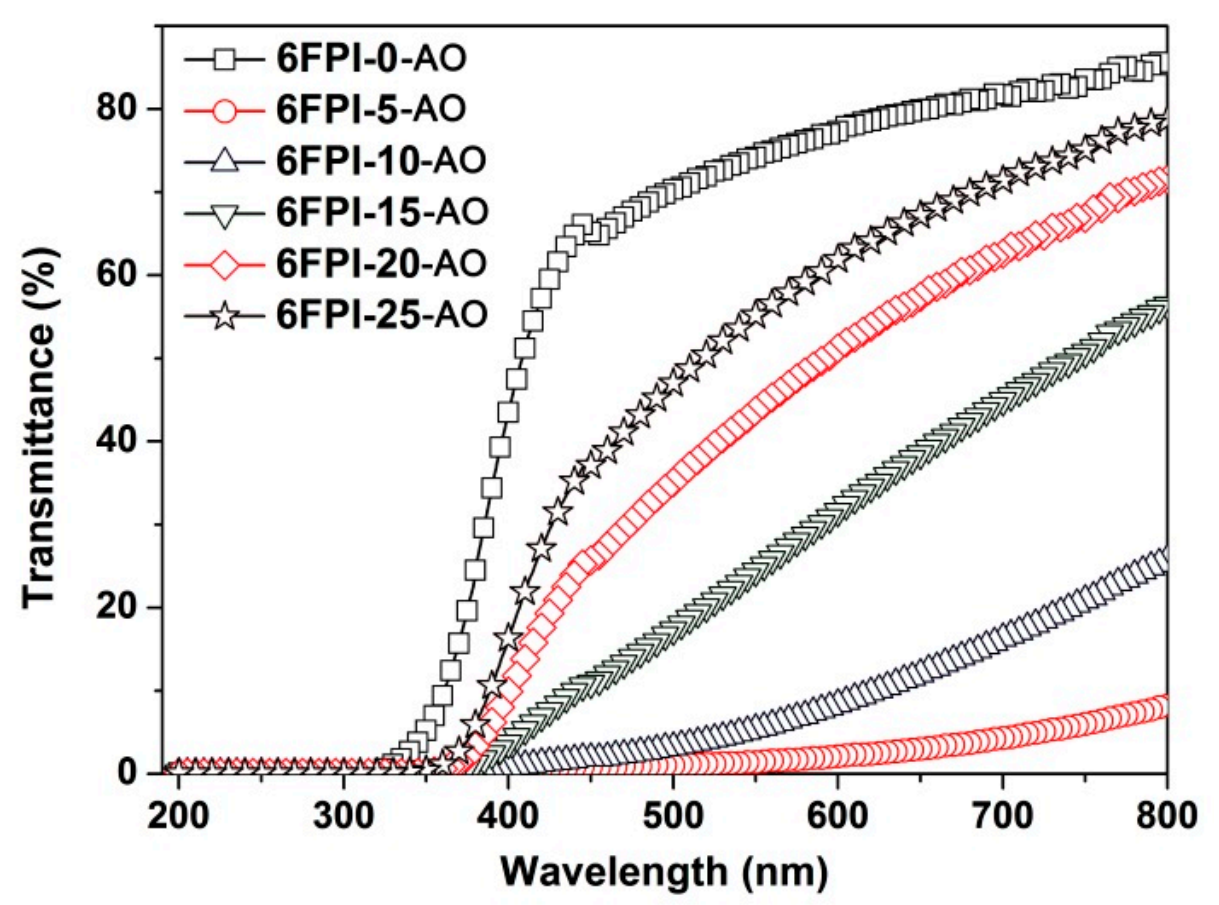

Figure 15. UV-Vis spectra of 6FPI-POSS films after AO exposure.

It has been well established that some specific elements, such as silicon, phosphorus, titanium, and so on could endow the PI films self-passivating or self-healing features in $\mathrm{AO}$ environments due to the potential ability for forming the passivation layers of silicate, phosphate, titanate, or the other inorganic oxides when the functional PI films were exposed to AO environments [28]. For the current PI composite films, such passivation layers were also detected, which could be found in the SEM measurement shown in Figure 16. For the pristine 6FPI-0-AO film, carpet-like micromorphology was observed after AO exposure, which is the typical characteristic of the AO-eroded polymer surface. Linear weight loss was found for the system. With the contents of the TSP-POSS additives in PI films increased from 0 to $15 \mathrm{wt} \%$, the AO-eroded surface gradually became rough. When the content of TSP-POSS additives was over $20 \mathrm{wt} \%$, the AO-eroded surface gradually became smooth. For the 6FPI-25-AO sample, clear passivation layers were observed on the surface. For the 6FPI-X-AO films, the rough surface might prohibit the transmission of visible light, while the smooth surface was beneficial for the penetration of visible light. Thus, the 6FPI-X-AO films showed the $T_{450}$ trends showing in Figure 15.

The surface roughness of AO-exposed PI films was investigated by AFM measurements and the change of surface morphology was also confirmed. The 2D AFM images of AO-exposed PI films were shown in Figure 17. It can be observed that the surface roughness of the AO-exposed 6FPI-X-AO films was markedly increased than those of unexposed 6FPI-X-AO films, which are shown in Figure 7. The roughness of the AO-exposed PI films showed a downward trend when TSP-POSS content was higher than $15 \mathrm{wt} \%$. The 6FPI-25-AO composite film exhibited the lowest roughness with the $R_{\mathrm{a}}$ and $R_{\mathrm{q}}$ values of $55.6 \mathrm{~nm}$ and $70.4 \mathrm{~nm}$, respectively. It might be due to the formation of the continuous and dense passivation layer onto the surface of AO-exposed 6FPI films. 
(a)

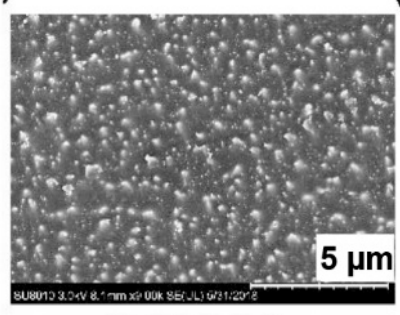

6FPI-0-AO

(d)

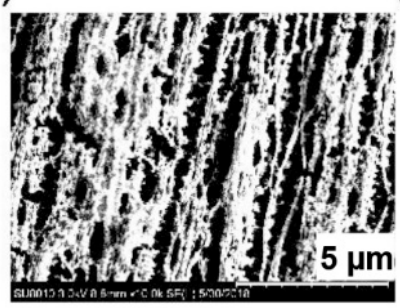

6FPI-15-AO (b)

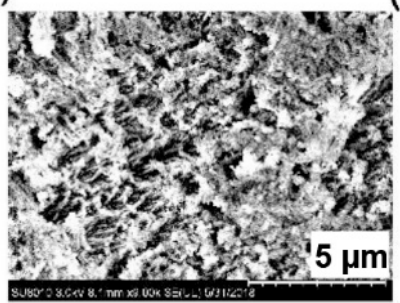

6FPl-5-AO

(e)

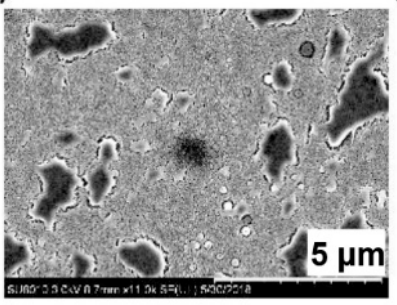

6FPI-20-AO (c)

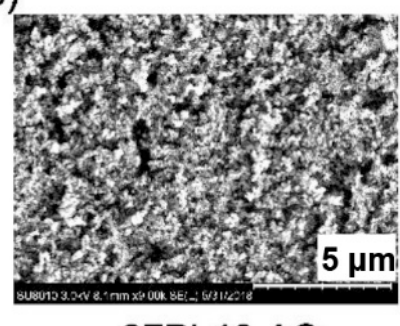

(f)

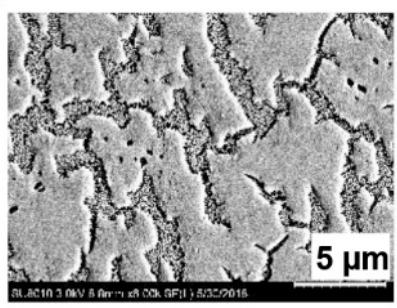

6FPI-25-AO

Figure 16. SEM images of 6FPI-X-AO films after $\mathrm{AO}$ exposure. (a) 6FPI-0-AO, (b) 6FPI-5-AO, (c) 6FPI-10-AO, (d) 6FPI-15-AO, (e) 6FPI-20-AO, (f) 6FPI-25-AO.

(a)

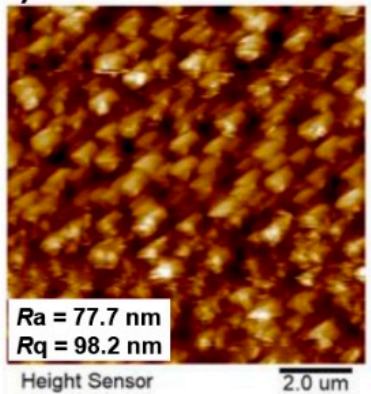

(d)

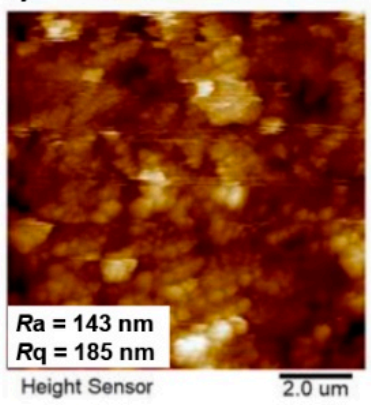

(b)

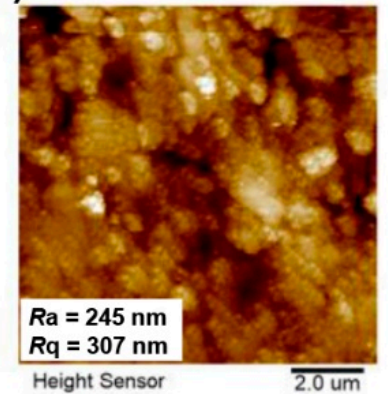

(e)

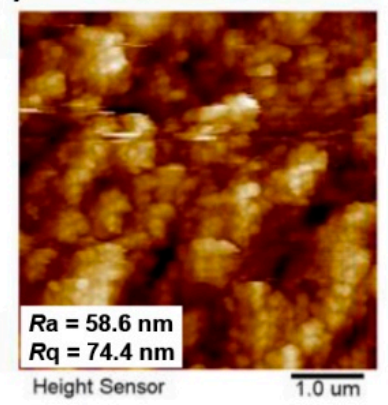

(c)

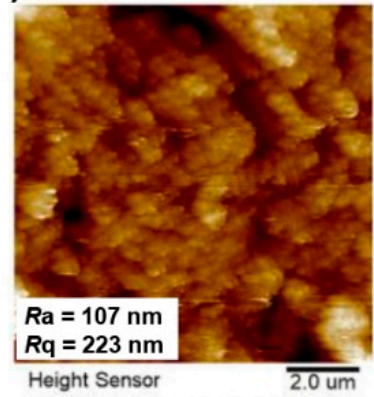

(f)

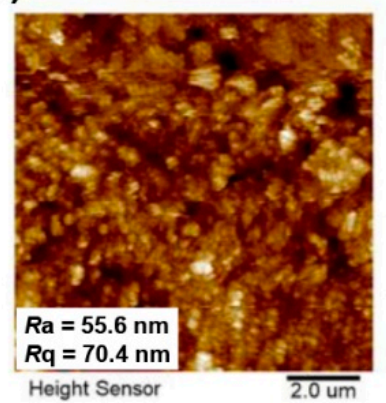

Figure 17. The $2 \mathrm{D}$ AFM images $(10.0 \mu \mathrm{m} \times 10.0 \mu \mathrm{m})$ of 6 FPI-X-AO films after AO exposure. (a) 6FPI-0-AO, (b) 6FPI-5-AO, (c) 6FPI-10-AO, (d) 6FPI-15-AO, (e) 6FPI-20-AO, (f) 6FPI-25-AO.

The relative atomic concentrations of the AO-exposed and unexposed films measured by XPS were tabulated in Table 5. As shown in the table, the relative atomic concentration of $\mathrm{C}$ element onto the surface of the 6FPI-X-AO films (except for 6FPI-0-AO) decreased apparently after $\mathrm{AO}$ exposure, whereas the relative atomic concentration of $\mathrm{O}$ and $\mathrm{Si}$ elements increased greatly. The change of Si element on the surface of PI composite films before and after $\mathrm{AO}$ exposure was further analyzed, and the obtained high-resolution XPS spectra were shown in Figure 18. It can be clearly observed that the peak intensity of $\mathrm{Si} 2 \mathrm{p}$ on the surface of $\mathrm{AO}$-exposed films gradually increased with the increasing contents 
of TSP-POSS additives, and the binding energy of Si2p also increased. For example, the binding energy peak of Si2p on the surface of the 6FPI-15 film shifted from $102.31 \mathrm{eV}$ before exposure to $103.34 \mathrm{eV}$ after exposure. The apparent shift of the binding energy peak of Si2p at $\sim 1.0 \mathrm{eV}$ after $\mathrm{AO}$ exposure indicated that the $\mathrm{Si}$ element changes from Si-O-Si structure on the surface of the $6 \mathrm{FPI}-15$ film to $\mathrm{SiO}_{2}$ structure for $6 \mathrm{FPI}-15-\mathrm{AO}$ film. The molar ratio of Si element to O element is close to 1:2 as shown in Table 5. These results demonstrated that the formation of the silica passivation layer on the surface of PI composite films, which could be a protective layer for the underlying polymer materials.

Table 5. XPS results for the AO-exposed and unexposed PI films.

\begin{tabular}{ccccccccccc}
\hline & \multicolumn{8}{c}{ Relative Atomic Concentration (\%) } \\
\cline { 2 - 10 } Samples & \multicolumn{9}{c}{ Unexposed Samples } & \multicolumn{4}{c}{ AO-exposed Samples } \\
\cline { 2 - 11 } & Si2p & C1s & O1s & N1s & F1s & Si2p & C1s & O1s & N1s & F1s \\
\hline 6FPI-0 & 0 & 75.74 & 12.44 & 2.58 & 6.58 & 0 & 70.81 & 18.03 & 2.62 & 4.54 \\
6FPI-5 & 5.09 & 66.58 & 19.08 & 3.67 & 4.39 & 18.34 & 35.80 & 40.43 & 1.65 & 3.78 \\
6FPI-10 & 6.24 & 67.07 & 16.07 & 2.09 & 8.28 & 20.08 & 31.16 & 44.15 & 1.14 & 3.47 \\
6FPI-15 & 3.14 & 76.48 & 13.57 & 1.64 & 4.44 & 17.87 & 36.74 & 40.18 & 1.74 & 3.47 \\
6FPI-20 & 2.96 & 64.63 & 18.08 & 3.52 & 7.56 & 21.25 & 28.07 & 46.51 & 1.06 & 3.10 \\
6FPI-25 & 9.43 & 66.55 & 18.74 & 1.92 & 3.36 & 17.30 & 39.29 & 38.33 & 1.84 & 3.24 \\
\hline
\end{tabular}
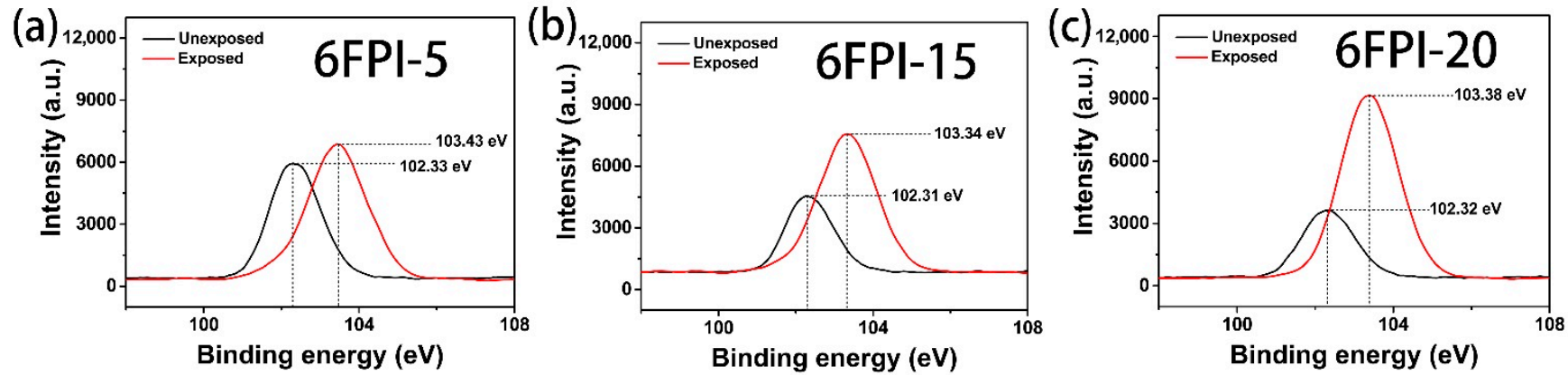

Figure 18. XPS spectra of Si2p for AO-exposed and unexposed 6FPI-POSS composite films with total AO fluence of $4.02 \times 10^{20}$ atom $/ \mathrm{cm}^{2}$. (a) 6 FPI-5; (b) 6FPI-15; (c) 6FPI-20.

\section{Conclusions}

In summary, an optically transparent film with good dielectric properties and good $\mathrm{AO}$ resistance in simulated LEO environments has been successfully prepared. The properties of 6FPI were endowed with the synergistic effects of fluoro-containing PI matrix and the TSP-POSS additives. The 6FPI- 25 composite film at the thickness of $25 \mu \mathrm{m}$ possessed high optical transparency $\left(\lambda_{\text {cut }}=292 \mathrm{~nm}, T_{450}=84.7 \%\right.$, haze $\left.=5.14 \%\right)$ and was nearly colorless $\left(a^{*}=-1.34, b^{*}=3.80, L^{*}=95.78\right)$. Meanwhile, the $6 \mathrm{FPI}-25$ film possessed good dielectric properties with low $D_{\mathrm{k}}$ and $D_{\mathrm{f}}\left(D_{\mathrm{k}}=2.52\right.$ at $1 \mathrm{MHz}, D_{\mathrm{f}}=0.010$ at $\left.1 \mathrm{MHz}\right)$ and good thermal stability with the $T_{5 \%}$ of $494{ }^{\circ} \mathrm{C}$. Moreover, the AO erosion yield of 6FPI-25 composite film was $0.40 \times 10^{-24} \mathrm{~cm}^{3} /$ atom after AO exposure at a fluence of $4.02 \times 10^{20}$ atoms $/ \mathrm{cm}^{2}$. The XPS and SEM measurements confirmed that the passivation layer formed on the surface of the exposed film could protect the underlying material from further AO attack. The transparent PI composite films with good dielectric properties and long-term sustainability in AO environments are good candidates for antenna substrates in LEO aerospace applications. 
Author Contributions: Conceptualization, J.-g.L.; Methodology, B.-h.W., H.-1.W. and J.-g.L.; Investigation, Y.Z., H.W. and Y.-c.A.; Data curation, Y.Z., X.-x.Z. and Y.-c.A.; Writing-original draft preparation, Y.Z.; Writing-review and editing, B.-h.W. and J.-g.L.; Supervision, J.-g.L. and H.-1.W.; Funding acquisition, J.-g.L. All authors have read and agreed to the published version of the manuscript.

Funding: This work was supported by the Shandong Key Research and Development Program (No. 2019JZZY020235).

Institutional Review Board Statement: Not applicable.

Informed Consent Statement: Not applicable.

Data Availability Statement: Data is contained within the article.

Conflicts of Interest: The authors declare no conflict of interest.

\section{References}

1. Lokman, A.H.; Soh, P.J.; Azemi, S.N.; Lago, H.; Podilchak, S.K.; Chalermwisutkul, S.; Jamlos, M.F.; Al-Hadi, A.A.; Akkaraekthalin, P.; Gao, S. A Review of Antennas for Picosatellite Applications. Int. J. Antennas Propag. 2017, 2017, 1-17. [CrossRef]

2. Mahmoud, W.M.; ElFiky, D.; Robaa, S.M.; ElNawawy, M.S.; Yousef, S.M. Effect of Atomic Oxygen on LEO CubeSat. Int. J. Aeronaut. Space Sci. 2021, 22, 1-8. [CrossRef]

3. Smith, C.T.G.; Delkowki, M.; Anguita, J.V.; Cox, D.C.; Haas, C.; Silva, S.R.P. Complete Atomic Oxygen and UV Protection for Polymer and Composite Materials in a Low Earth Orbit. ACS Appl. Mater. Interfaces 2021, 13, 6670-6677. [CrossRef]

4. Novikov, L.; Chernik, V.N.; Naumov, S.F.; Sokolova, S.P.; Gerasimova, T.I.; Kurilyonok, A.O.; Smirnova, T.N. Degradation Testing of Spacecraft Materials for Long Flights in Low Earth Orbit. J. Spacecr. Rocket. 2006, 43, 534-538. [CrossRef]

5. Qian, M.; Liu, G.; Zhou, B.; Xuan, X.Y.; Niu, Y.P.; Gong, S.Q. Atomic oxygen durable ultra-black polyimide composite films in solar spectrum. Polym. Degrad. Stab. 2020, 175, 109133/1-109133/13. [CrossRef]

6. Minton, T.K.; Wu, B.; Zhang, J.; Lindholm, N.F.; Abdulagatov, A.I.; O'Patchen, J.; George, S.; Groner, M.D. Protecting Polymers in Space with Atomic Layer Deposition Coatings. ACS Appl. Mater. Interfaces 2010, 2, 2515-2520. [CrossRef]

7. Wang, X.; Li, Y.; Qian, Y.; Qi, H.; Li, J.; Sun, J. Mechanically Robust Atomic Oxygen-Resistant Coatings Capable of Autonomously Healing Damage in Low Earth Orbit Space Environment. Adv. Mater. 2018, 30, e1803854. [CrossRef] [PubMed]

8. Fuchs, W.K.; Sarantes, C.; Prine, N.; Gu, X.; Patton, D.L.; Wiggins, J. Atomic Oxygen-Resistant Epoxy-amines Containing Phenylphosphine Oxide as Low Earth Orbit Stable Polymers. ACS Appl. Polym. Mater. 2021, 3, 178-190. [CrossRef]

9. He, Y.; Suliga, A.; Brinkmeyer, A.; Schenk, M.; Hamerton, I. Atomic oxygen degradation mechanisms of epoxy composites for space applications. Polym. Degrad. Stab. 2019, 166, 108-120. [CrossRef]

10. Dever, J.A.; Miller, S.K.; Sechkar, E.A.; Wittberg, T.N. Space environment exposure of polymer films on the materials international space station experiment: Results from MISSE 1 and MISSE 2. High Perform. Polym. 2008, 20, 371-387. [CrossRef]

11. Li, X.; Al-Ostaz, A.; Jaradat, M.; Rahmani, F.; Nouranian, S.; Rushing, G.; Manasrah, A.; Alkhateb, H.; Finckenor, M.; Lichtenhan, J. Substantially enhanced durability of polyhedral oligomeric silsequioxane-polyimide nanocomposites against atomic oxygen erosion. Eur. Polym. J. 2017, 92, 233-249. [CrossRef]

12. Wu, B.; Zhang, Y.; Yang, D.; Yang, Y.; Yu, Q.; Che, L.; Liu, J. Self-healing anti-atomic-oxygen phosphorus-containing polyimide film via molecular level incorporation of nanocage trilsilanolphenyl POSS: Preparation and characterization. Polymers 2019, 11, 1013. [CrossRef]

13. Khaleel, H.R.; Al-Rizzo, H.M.; Abbosh, A.I. Design, fabrication, and testing of flexible antennas. In Advancement in Microstrip Antennas with Recent Applications; Kishk, A., Ed.; Intech: Rejeka, Croatia, 2013; pp. 163-383.

14. Martin, S.J.; Godschalx, J.P.; Mills, M.E.; Shaffer, E.O., II; Townsend, P.H. Development of a low-dielectric-constant polymer for the fabrication of integrated circuit interconnect. Adv. Mater. 2000, 12, 1769-1778. [CrossRef]

15. Alibakhshikenari, M.; Virdee, B.S.; See, C.H.; Abd-Alhameed, R.A.; Falcone, F.; Limiti, E. High-gain metasurface in polyimide on-chip antenna based on CRLH-TL for sub-terahertz integrated circuits. Sci. Rep. 2020, 10, 4298. [CrossRef]

16. Cang, D.; Wang, Z.; Qu, H. A Polyimide-Based Flexible Monopole Antenna Fed by a Coplanar Waveguide. Electron. 2021, 10, 334. [CrossRef]

17. Khaleel, H.R.; Al-Rizzo, H.M.; Rucker, D.G. Compact Polyimide-Based Antennas for Flexible Displays. J. Disp. Technol. 2012, 8, 91-97. [CrossRef]

18. Beer, S.; Gulan, H.; Rusch, C.; Zwick, T. Integrated 122-GHz Antenna on a Flexible Polyimide Substrate with Flip Chip Interconnect. IEEE Trans. Antennas Propag. 2012, 61, 1564-1572. [CrossRef]

19. Meador, M.A.B.; Wright, S.; Sandberg, A.; Nguyen, B.N.; Van Keuls, F.W.; Mueller, C.H.; Solis, R.R.; Miranda, F.A. Low Dielectric Polyimide Aerogels as Substrates for Lightweight Patch Antennas. ACS Appl. Mater. Interfaces 2012, 4, 6346-6353. [CrossRef]

20. Meador, M.A.; McMillon, E.; Sandberg, A.; Barrios, E.; Wilmoth, N.G.; Mueller, C.H.; Miranda, F.A. Dielectric and Other Properties of Polyimide Aerogels Containing Fluorinated Blocks. ACS Appl. Mater. Interfaces 2014, 6, 6062-6068. [CrossRef]

21. Fang, G.; Li, H.; Liu, J.; Ni, H.; Yang, H.; Yang, S. Intrinsically Atomic-oxygen-resistant POSS-containing Polyimide Aerogels: Synthesis and Characterization. Chem. Lett. 2015, 44, 1083-1085. [CrossRef] 
22. Kravtsova, V.; Umerzakova, M.; Iskakov, R.; Korobova, N. Electrical Properties of Fluoro-Containing Alicyclic Polyimides. J. Chem. Chem. Eng. 2015, 9, 31-37. [CrossRef]

23. Wright, J.S.; Jones, A.; Farmer, B.; Rodman, D.L.; Minton, T.K. POSS-enhanced colorless organic/inorganic nanocomposite (CORIN®) for atomic oxygen resistance in low earth orbit. CEAS Space J. 2021, 1-15. [CrossRef]

24. Leu, C.-M.; Chang, A.Y.-T.; Wei, K.-H. Polyimide-Side-Chain Tethered Polyhedral Oligomeric Silsesquioxane Nanocomposites for Low-Dielectric Film Applications. Chem. Mater. 2003, 15, 3721-3727. [CrossRef]

25. Grove, T.T.; Masters, M.F.; Miers, R.E. Determining dielectric constants using a parallel plate capacitor. Am. J. Phys. 2005, 73, 52-56. [CrossRef]

26. Wu, H.; Zhang, Y.; Guo, Y.D.; Qi, H.R.; An, Y.C.; Jia, Y.J.; Tan, Y.Y.; Liu, J.G.; Wu, B.H. Preparation and properties of intrinsically atomic-oxygen resistant polyimide films containing polyhedral oligometric silsesquioxane (POSS) in the side chains. Polymers 2020, 12, 2865. [CrossRef]

27. Zhang, Y.; Wu, H.; Guo, Y.-D.; Yang, Y.-B.; Yu, Q.; Liu, J.-G.; Wu, B.-H.; Lv, F.-Z. Atomic Oxygen-Resistant Polyimide Composite Films Containing Nanocaged Polyhedral Oligomeric Silsesquioxane Components in Matrix and Fillers. Nanomaterials 2021, 11, 141. [CrossRef]

28. Gouzman, I.; Grossman, E.; Verker, R.; Atar, N.; Bolker, A.; Eliaz, N. Advances in Polyimide-Based Materials for Space Applications. Adv. Mater. 2019, 31, e1807738. [CrossRef]

29. Simpson, J.; St Clair, A. Fundamental insight on developing low dielectric constant polyimides. Thin Solid Films 1997, 308-309, 480-485. [CrossRef]

30. Qian, M.; Murray, V.J.; Wei, W.; Marshall, B.C.; Minton, T.K. Resistance of POSS Polyimide Blends to Hyperthermal Atomic Oxygen Attack. ACS Appl. Mater. Interfaces 2016, 8, 33982-33992. [CrossRef]

31. Amin, M.; Samy, H.; Küpper, J. Robust and Accurate Computational Estimation of the Polarizability Tensors of Macromolecules. J. Phys. Chem. Lett. 2019, 10, 2938-2943. [CrossRef]

32. Zhang, Y.; Liu, J.; Wu, X.; Guo, C.; Qu, L.; Zhang, X. Trisilanolphenyl-POSS nano-hybrid poly(biphenyl dianhydride-pphenylenediamine) polyimide composite films: Miscibility and structure-property relationship. J. Polym. Res. 2018, 25, 139. [CrossRef]

33. Leger, L.J.; Visentine, J.T. A consideration of atomic oxygen interactions with the Space Station. J. Spacecr. Rocket. 1986, $23,505-511$. [CrossRef] 